\title{
Photocatalyzed Transformation of Free Carbohydrates
}

\author{
Mehdi Omri ${ }^{1}$, Frédéric Sauvage ${ }^{2}$, Séma Golonu ${ }^{1,2}$, Anne Wadouachi ${ }^{1}$ and \\ Gwladys Pourceau 1,*(D) \\ 1 Laboratoire de Glycochimie, des Antimicrobiens et des Agroressources (LG2A) UMR CNRS 7378-Institut de \\ Chimie de Picardie FR 3085, Université de Picardie Jules Verne, 33 rue Saint Leu, FR-80039 Amiens CEDEX, \\ France; mehdi.omri@sattnord.fr (M.O.); sema.golonu@u-picardie.fr (S.G.); \\ anne.wadouachi@u-picardie.fr (A.W.) \\ 2 Laboratoire de Réactivité et Chimie des Solides (LRCS), UMR CNRS 7314 - Institut de Chimie de Picardie \\ FR 3085, Université de Picardie Jules Verne, 33 rue Saint Leu, FR-80039 Amiens CEDEX, France; \\ frederic.sauvage@u-picardie.fr \\ * Correspondence: gwladys.pourceau@u-picardie.fr; Tel.: +33-322-827-476
}

Received: 27 November 2018; Accepted: 17 December 2018; Published: 19 December 2018

\begin{abstract}
In the growing context of sustainable chemistry, one of the challenges of organic chemists is to develop efficient and environmentally friendly methods for the synthesis of high-added-value products. Heterogeneous photocatalytic transformations have brought revolution in this regard, as they take advantage of an unlimited source of energy (solar light) or artificial UV light to onset organic chemical modifications. The abundance of free carbohydrates as chemical platform feedstock offers a great opportunity to obtain a variety of industrial interest compounds from biomass. Due to their chirality and polyfunctionality, the conversion of sugars generally requires multi-step protocols with protection/deprotection steps and hazardous chemical needs. In this context, several selective and eco-friendly methodologies are currently under development. This review presents a state of art of the recent accomplishments concerning the use of photocatalysts for the transformation and valorization of free carbohydrates. It discusses the approaches leading to the selective oxidation of free sugars, their degradation into organic chemicals, or their use for hydrogen production.
\end{abstract}

Keywords: photocatalysis; selective transformation of free carbohydrates; glycochemistry

\section{Introduction}

Over the last few decades, amid the growing concern about the preservation of the planet, chemists and industries have prompted the development of eco-friendly synthetic methods leading to high value-added products from biomass. Indeed, biomass is an inexpensive renewable and worldwide available resource. It consists of three major families: polysaccharides (starch, cellulose, hemicellulose, chitin etc.), amino acids, and lipids. Among them, carbohydrates are the most abundant valuable materials. The use of these as biomass feedstock to prepare environmentally friendly products is therefore very attractive [1]. Many value-added products, such as detergents, pharmaceuticals, polymers, and cosmetics, can be obtained by different modifications of carbohydrates (oxidation, reduction, isomerization, glycosylation ... ) [2]. The backbone of free polysaccharides is composed of linear or ramified chains of diverse monosaccharides (Figure 1). It confers them a rich and varied structure, exhibiting not only a large number of hydroxyl functions, but also amino acids, sulfate groups, etc. However, the chemical modification of these chiral polyhydroxylated compounds into well-defined carbohydrate derivatives is often characterized by multi-step strategies, with protection/deprotection steps, which generally use unsafe chemicals and have a poor atom efficiency: i.e., if one hydroxyl is supposed to react, the other functions, and more particularly the numerous hydroxyl groups, need to be masked. 


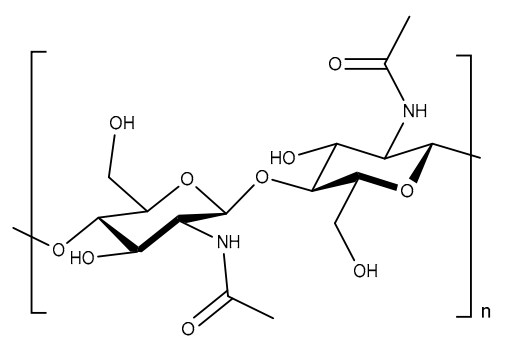

Chitin

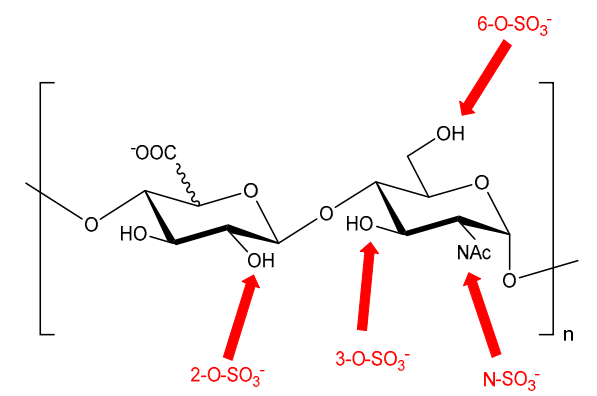

Heparan sulfate

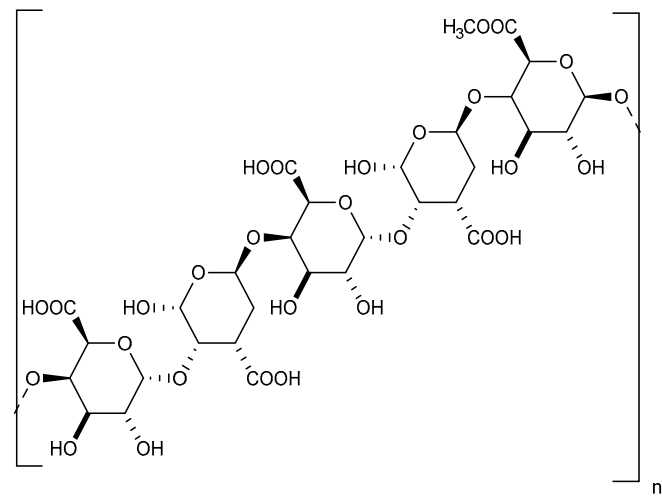

Pectin

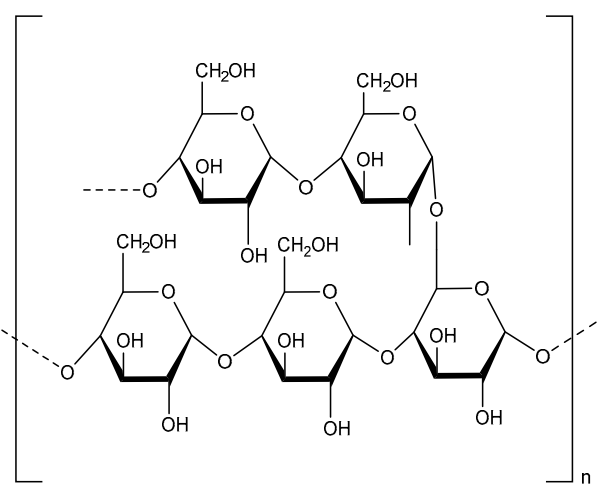

Starch

Figure 1. Examples of some natural polysaccharides.

For example, the synthesis of 3'-keto-kanamycin B from kanamycin B needs an 11-step protocol, leading to only a $10 \%$ overall yield [3]. Among these 11 steps, 10 are protection/deprotection reactions, necessary to selectively oxidize the 3'-OH into ketone. Moreover, the glycosidic linkage is particularly sensitive, which limits the use of post-modification strategies, and thus favors step-by-step procedures. These strategies are characterized by the extensive use of protective groups, high time consumption, and a low global yield: e.g., 55 steps are necessary to synthesize fondaparinux (commercialized Arixtra ${ }^{\circledR}$ used as anticoagulant) [4].

The development of economic, efficient, and eco-friendly methodologies for the transformation of carbohydrates constitutes a challenge for glycochemists. It also represents an opportunity to enhance the use of sugars as starting sources for the synthesis of more complex derivatives of pharmaceutical interest, or as detergents, for example. The use of free sugars as starting materials is a first step towards improving the overall process sustainability. This is particularly well-addressed in recent reviews related to the use of unprotected carbohydrates in chemical synthesis, to which we kindly invite readers to refer to for more information [5,6]. A second approach lies in the development of green procedures that allow the modification of mono- and oligosaccharides under mild conditions.

In this context, heterogeneous photocatalytic transformation constitutes a viable and environmentally friendly procedure ideally driven by sunlight absorption. The utilization of solar energy, an abundant and renewable source, to drive organic syntheses is very attractive: the grail of mimicking the Z-scheme of the natural photosynthetic mechanism to obtain products of interest (fuels, chemicals etc.) is common to many scientists [7]. Most photocatalytic transformations are performed by means of semiconducting materials (SC). When photons are greater in energy than the SC bandgap value, light absorption endorses charge separation processes in which electrons are promoted from the valence band (VB) to the conduction band (CB), leaving an oxidizing hole in the VB (Figure 2). 


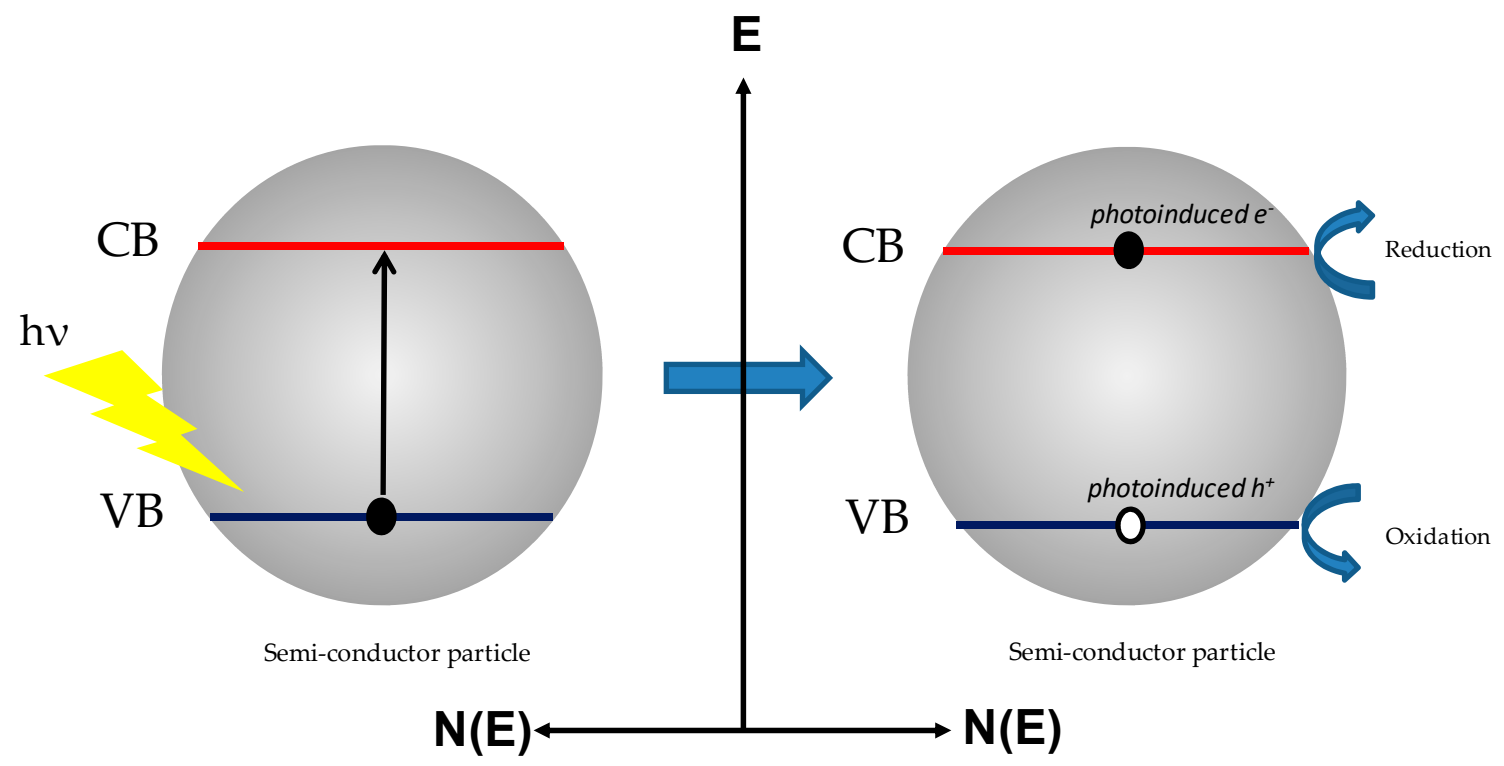

Figure 2. Light-induced charge separation process in a semi-conducting particle.

During the last decades, many efforts were given to designing appropriate semiconductor materials exhibiting panchromatic light absorption, long-lived excited states yielding high photocatalytic performances, particularly for oxidation reactions. $\mathrm{TiO}_{2}$ in its different polymorph phases (anatase, rutile, mix anatase-rutile) is one of the most promising photocalysts thanks to its high chemical robustness and high reactivity [8]. However, $\mathrm{TiO}_{2}$ suffers from several drawbacks, the most important being its large band-gap value of $3.20 \mathrm{eV}$, restricting its absorption to UV light $(\lambda<390 \mathrm{~nm})$. Note that photons with an energy corresponding to less than a $410 \mathrm{~nm}$ wavelength (UV light) stand for $c a .4 \%$ of the solar flux below the atmosphere ( $c a .50 \%$ is visible light). This can be mitigated by its $3 \mathrm{~d}^{0}$ electronic configuration for which the opto-electronic characteristics become particularly sensitive to the introduction of electronic and structural defects, leading to a narrowing of the bandgap. $\mathrm{TiO}_{2}$-based photocatalysts are generally poorly selective, especially in aqueous media. This is mainly attributed to the high oxidizing strength of the $\mathrm{VB}$ holes $\left(\mathrm{E}_{\mathrm{VB}} \approx 2.8 \mathrm{~V}\right.$ vs. $\left.\mathrm{ENH}\right)$, leading to the formation of highly reactive radicals such as $\mathrm{HO}^{-}, \mathrm{O}_{2}{ }^{-}$, or $\mathrm{HO}_{2}$, which in turn will unselectively react with the targeted molecule. Several methodologies, some of which will be described in the section below, allow the low light absorption capability in the visible range to be overcome, including the addition of plasmonic nanoparticles such as gold (Au NPs), aliovalent doping, dye sensitization, and so on [9-11].

These properties have opened new perspectives for the application of semiconductor photocatalysts to the transformation of organic compounds [12-14]. Oxidation reactions are particularly represented in the literature [15]. Photocatalysis can also improve a wide range of organic reactions, such as C-C coupling [16], the hydroamination of alkynes with anilines [17], and the reduction of nitroaromatics [18], among others. Selective photocatalytic transformation of biomass-derived compounds is especially a topic of great interest [19]. Nevertheless, the modification of free carbohydrates by a photocatalytic route remains little explored. In 2009, Colmenares et al. published a review concerning the use of photocatalysts for the transformation of lignocellulosic biomass, but with only a few examples of carbohydrates [20]. The review we propose aims at providing a critical in-depth description of the recent advances related to the transformation of free sugars using photocatalytic procedures. It is divided into two sections based on the targeted transformation, namely selective oxidation and degradation (into organic or inorganic compounds). The first one leads to the production of gluconic acid, which is an important chemical platform $(100,000$ tons are produced per year, by biotechnological processes). The second one leads to $\mathrm{H}_{2}$ production, a very hot topic for fossil energy replacement. 


\section{Selective Oxidation}

Among the transformation of sugars, the selective oxidation of the anomeric and/or primary $\mathrm{OH}$ functions is of particular interest since it leads to aldonic, uronic, and aldaric acids. For example, the selective oxidation of glucose at $C-1$ position or C-1/C-6 positions leads to gluconic and glucaric acids, respectively (Scheme 1). These biocompatible and biodegradable products are widely used in several areas, such as food, paper, cosmetics, and pharmaceutical industries. They are also considered as important chiral platform molecules. For instance, glucaric acid is one of the top 12 platform chemicals from biomass and is a promising alternative for providing adipic acid widely used in the polymers and textile industries [21-23].

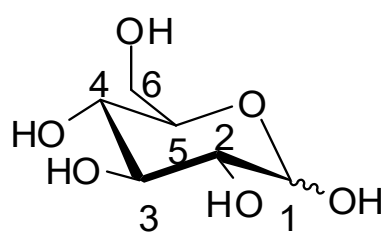

D-Glucose

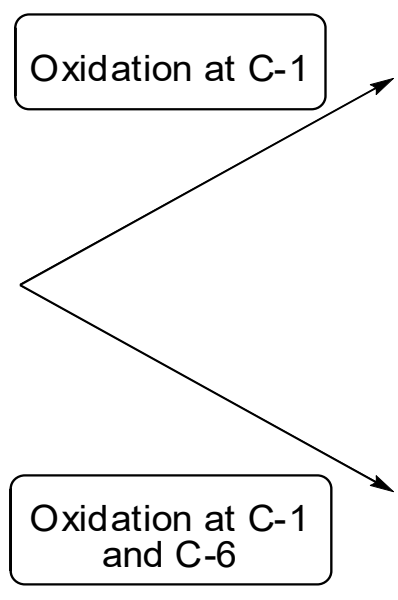<smiles>O=C(O)[C@H](O)[C@@H](O)[C@H](O)[C@H](O)CO</smiles>

Gluconic acid<smiles>O=C(O)[C@@H](O)[C@H](O)[C@@H](O)C(=O)O</smiles>

Glucaric acid

Scheme 1. Oxidation of glucose into corresponding gluconic and glucaric acids.

Photo-oxidation of free sugars was initially developed using $\mathrm{TiO}_{2}$ semiconductors, owing to their low cost, non-toxicity, thermal stability, and ability against photo-corrosion. Glucose as a starting material remains the most studied model system. Initially, Colmenares et al. reported the efficiency of heterogeneous nano-titania photocatalysts for the selective photo-oxidation of glucose into two acid derivatives (glucaric and gluconic acids), and a $\mathrm{C}_{5}$-reduced compound (arabitol) [24]. The photolysis reaction was achieved under air oxygen as an oxidant mediator using titania photocatalysts synthesized by a sonication-induced sol-gel procedure $\left(\mathrm{TiO}_{2}\right.$ (US)) or using a reflux method $\left(\mathrm{TiO}_{2}(\mathrm{R})\right)$ and commercially available Degussa $\mathrm{P}_{25}$. $\mathrm{TiO}_{2}$ (US) showed remarkable textural, structural, and optical features (high specific surface area $65 \mathrm{~m}^{2} / \mathrm{g}$, low band gap energy value $3.09 \mathrm{eV}$, and nanometric anatase phase of 12.7-nm crystallite size) compared to $\mathrm{TiO}_{2}$ (R) (SSA: $54 \mathrm{~m}^{2} / \mathrm{g}$, band gap energy value: $3.17 \mathrm{eV}$ and nanometric anatase phase of 12.4-nm crystallite size) and P25 (SSA: $51 \mathrm{~m}^{2} / \mathrm{g}$, band gap energy value: $3.20 \mathrm{eV}$ and anatase/rutile phases). The efficiency of the three photocatalysts was compared. Interestingly, the influence of the different photolysis parameters, such as solvent composition and irradiation time, was also discussed (Table 1). The results showed, at best, $11 \%$ glucose conversion after $10 \mathrm{~min}$ of irradiation with a selectivity of more than $70 \%$ related to total organic compounds. This was achieved by using the $\mathrm{TiO}_{2}$ (US) in a $\mathrm{H}_{2} \mathrm{O} / \mathrm{CH}_{3} \mathrm{CN}$ (1:1) mixture. Apart from arabitol, gluconic, and glucaric acids in the liquid phase, $\mathrm{CO}_{2}$ coming from total mineralization was also detected. Often under-estimated in the literature, both the lamp spectrum and light flux play a critical role in the photocatalytic performances of the photocatalyst. For real applications and for the sake of standardization in the measurements, one should consider the utilization of a simulated solar spectrum closed to photovoltaic standards, such as Air Mass $1.5 \mathrm{G}$ conditions $\left(\mathrm{P}_{\mathrm{ill}}=1000 \mathrm{~W} / \mathrm{m}^{2}\right)$. In this case, 
incident light was produced by a $125 \mathrm{~W}$ mercury lamp, which only provides UV irradiation between 300 and $400 \mathrm{~nm}\left(\lambda_{\max }=365 \mathrm{~nm}\right)$. This corresponds to the range in which $\mathrm{TiO}_{2}$ absorbs the most.

Table 1. Effects of solvent composition on glucose conversion and selectivity towards glucaric/gluconic acids and arabitol after 10 min of light irradiation from Colmenares et al. [24].

\begin{tabular}{|c|c|c|c|c|c|c|}
\hline \multirow{3}{*}{ Photocatalyst } & \multicolumn{6}{|c|}{ Solvent Composition } \\
\hline & \multicolumn{2}{|c|}{$10 \% \mathrm{H}_{2} \mathrm{O} / 90 \% \mathrm{CH}_{3} \mathrm{CN}$} & \multicolumn{2}{|c|}{$50 \% \mathrm{H}_{2} \mathrm{O} / 50 \% \mathrm{CH}_{3} \mathrm{CN}$} & \multicolumn{2}{|c|}{$100 \% \mathrm{H}_{2} \mathrm{O}$} \\
\hline & $\begin{array}{c}\text { Conversion } \\
(\%)\end{array}$ & $\underset{(\%)}{\sum \text { Selectivity }}$ & $\begin{array}{c}\text { Conversion } \\
(\%)\end{array}$ & $\underset{(\%)}{\sum \text { Selectivity }}$ & $\begin{array}{c}\text { Conversion } \\
(\%)\end{array}$ & $\begin{array}{c}\sum \text { Selectivity } \\
(\%)\end{array}$ \\
\hline P-25 & 60.4 & 16.8 & 67.3 & 8.5 & 78.8 & 0 \\
\hline $\mathrm{TiO}_{2}(\mathrm{R})$ & 35 & 32 & 41.5 & 17.2 & 50.3 & 0 \\
\hline $\mathrm{TiO}_{2}$ (US) & 28.8 & 31.7 & 11 & 71.3 & 41.2 & 0 \\
\hline
\end{tabular}

Reaction conditions: $C_{\text {glucose }}=2.8 \mathrm{mmol} \cdot \mathrm{L}^{-1}, 150 \mathrm{~mL}$ of mother solution, $150 \mathrm{mg}$ of photocatalyst, temperature

$30^{\circ} \mathrm{C}$, pressure 1 bar, $10 \mathrm{~min}$ illumination time.

The introduction of acetonitrile as in a solvent mixture is known to have a beneficial influence for selective photo-oxidation reactions $[25,26]$. This is attributed to its solvation power, which explains the better selectivity when using a 50-50 mixture (Table 1). The better selectivity of $\mathrm{TiO}_{2}$ (US) was attributed to the lower affinity of glucaric and gluconic acids for the $\mathrm{TiO}_{2}$ surface, according to the authors. This leads to their faster desorption from the surface, thus preventing subsequent mineralization. The authors also reported that the ultrasound-mediated procedure creates oxygen vacancies on the $\mathrm{TiO}_{2}$ surface, promoted by the cavitation phenomenon, leading to a shifting of the photocatalyst absorption more towards the visible range $\left(\lambda=409 \mathrm{~nm}\right.$ compared to $391 \mathrm{~nm}$ for $\mathrm{TiO}_{2}(\mathrm{R})$ and $387 \mathrm{~nm}$ for P25). However, the as-obtained $\mathrm{TiO}_{2}$ nanoparticles are very fine $(c a .12 .7 \mathrm{~nm})$ and the minimization of the energy surface from the very divided particles leads to a strong tendency towards aggregation. Their anchoring on the support was proposed to make handling easier and improve adsorption and photocatalytic properties [27]. The authors chose zeolite and silica owing to their interesting photocatalytic features: absence of light absorption in the UV-visible range, and good adsorption and diffusion properties. The efficiency of $\mathrm{TiO}_{2}$ supported on zeolite $\mathrm{Y}\left(\mathrm{TiO}_{2} / \mathrm{Ze}\right)$ and on silica $\left(\mathrm{TiO}_{2} / \mathrm{SiO}_{2}\right)$ was compared to that of previously described $\mathrm{TiO}_{2}$ (US) and commercial P25. The characterization of these two immobilized catalysts was carried out using UV-visible spectroscopy, $\mathrm{X}$-ray diffraction, and $\mathrm{N}_{2}$ adsorption-desorption isotherms. The quantum confinement of titania clusters within the support textures led to a slight increase in the band gap energy value from $3.18 \mathrm{eV}$ for $\mathrm{P} 25$ to 3.27 and $3.31 \mathrm{eV}$ for $\mathrm{TiO}_{2} / \mathrm{Ze}$ and $\mathrm{TiO}_{2} / \mathrm{SiO}_{2}$, respectively. A smaller anatase crystallite size (7.9 $\mathrm{nm}$ for $\mathrm{TiO}_{2} / \mathrm{Ze}$ compared to $17.6 \mathrm{~nm}$ in P25, determined by the Scherrer equation) could also be at the origin of this observation. Moreover, the loading of $\mathrm{TiO}_{2}$ on the surface led to a reduction of the specific surface area of the zeolite from 784 to $676 \mathrm{~m}^{2} / \mathrm{g}$, but did not have a significant impact on the specific surface area of $\mathrm{SiO}_{2}\left(c a .200 \mathrm{~m}^{2} / \mathrm{g}\right)$. Optimal conditions, namely water/acetonitrile (1:1), air as the oxidant, and $10 \mathrm{~min}$ illumination with a $125 \mathrm{~W}$ mercury lamp, led to a maximum of $15.5 \%$ conversion yield, with a selectivity towards sugar acids of around $68 \%$ when using $\mathrm{TiO}_{2} / \mathrm{Ze}$ (Table 2 ). Note that in this case, no arabitol was detected as a photocatalytic product. The improvement in the conversion efficiency by using the zeolite is explained by the improvement of the charge separation process since it is well-established in the literature that this promotes photo-induced electron-transfer reactions by minimizing electron-hole recombination [28]. In addition, the authors suggested that the negatively-charged zeolite framework may also play a critical role in the selectivity as it favors the desorption of acids as a result of electrostatic repulsion. 
Table 2. Effects of solvent composition on glucose conversion and selectivity towards glucaric/gluconic acids using $\mathrm{TiO}_{2}$ (US), Evonik P-25, $\mathrm{TiO}_{2} / \mathrm{SiO}_{2}$, and $\mathrm{TiO}_{2} /$ Zeolite after 10 min of light irradiation from Colmenares et al. [27].

\begin{tabular}{|c|c|c|c|c|c|c|}
\hline \multirow{3}{*}{ Photocatalyst } & \multicolumn{6}{|c|}{ Solvent Composition } \\
\hline & \multicolumn{2}{|c|}{$10 \% \mathrm{H}_{2} \mathrm{O} / 90 \% \mathrm{CH}_{3} \mathrm{CN}$} & \multicolumn{2}{|c|}{$50 \% \mathrm{H}_{2} \mathrm{O} / 50 \% \mathrm{CH}_{3} \mathrm{CN}$} & \multicolumn{2}{|c|}{$100 \% \mathrm{H}_{2} \mathrm{O}$} \\
\hline & $\begin{array}{c}\text { Conversion } \\
(\%)\end{array}$ & $\begin{array}{c}\sum \text { Selectivity } \\
(\%)\end{array}$ & $\begin{array}{c}\text { Conversion } \\
(\%)\end{array}$ & $\begin{array}{c}\sum \text { Selectivity } \\
(\%)\end{array}$ & $\begin{array}{c}\text { Conversion } \\
(\%)\end{array}$ & $\begin{array}{c}\sum \text { Selectivity } \\
(\%)\end{array}$ \\
\hline Evonik P-25 & 60.4 & 12.1 & 67.3 & 8.5 & 78.8 & 0 \\
\hline $\mathrm{TiO}_{2}$ (US) & 28.8 & 27.3 & 11 & 71.3 & 41.2 & 0 \\
\hline $\mathrm{TiO}_{2} / \mathrm{SiO}_{2}$ & 58.1 & 28.1 & 14 & 64.8 & 9.5 & 0 \\
\hline $\mathrm{TiO}_{2} /$ Zeolite & 49.2 & 29.5 & 15.5 & 68.1 & 13.7 & 0 \\
\hline
\end{tabular}

Reaction conditions: $C_{\text {glucose }}=2.8 \mathrm{mmol} \cdot \mathrm{L}^{-1}, 150 \mathrm{~mL}$ of mother solution, $150 \mathrm{mg}$ of photocatalyst, $\mathrm{T}=30^{\circ} \mathrm{C}, \mathrm{P}=1$ bar, 10 min illumination time.

Recently, Da Vià et al. reported for the first time the visible-light-mediated photo-oxidation of glucose catalyzed by unmodified titanium dioxide [29]. As previously mentioned, owing to its large bandgap, $\mathrm{TiO}_{2}$ is not photoactive in the visible range, and before this work, was not considered for visible-light driven selective photocatalysis. Nevertheless, after $4 \mathrm{~h}$ under visible light $(300 \mathrm{~W}$ Xenon lamp), a maximum of conversion of $42 \%$ was reached with low selectivity to gluconic acid $(7 \%)$ and $93 \%$ to other organics (arabinose, erythrose, glyceraldehyde, and formic acid) when using $2.8 \mathrm{mmol} \cdot \mathrm{L}^{-1}$ glucose solution (Scheme 2 ).
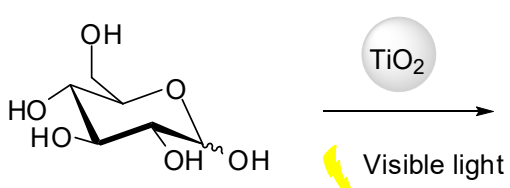

Glucose

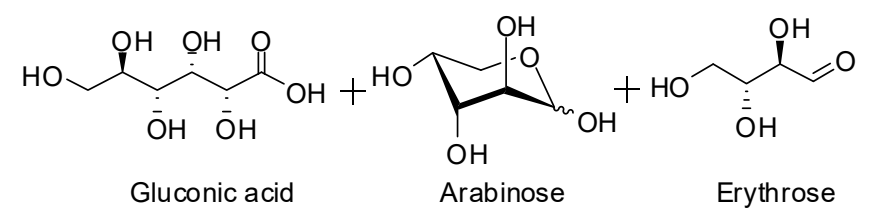<smiles>O=CC(O)CO</smiles>

Scheme 2. Photo-oxidation of D-glucose with unmodified $\mathrm{TiO}_{2}$ under visible light, developed by Da Vià et al. [29].

The photocatalytic activity of $\mathrm{TiO}_{2}$ under visible light is explained by the formation of a ligand-to-metal-charge-transfer (LMCT) in a $\mathrm{TiO}_{2}$-glucose complex The charge separation along the complex under light excitation leaves a positive charge on the glucose, which in turn will enhance its reactivity towards oxidation/desorption. Different parameters were studied, including the effect of glucose concentration, solvent, $\mathrm{TiO}_{2}$ crystalline structure (anatase, rutile, mix anatase/rutile), light source, lamp power, and filters. Glucose concentration seems to play a crucial role, with a high concentration disfavoring the conversion rate (Table 3). In addition, changing the light source to a Luzchem photoreactor equipped with a UVA lamp (112W) resulted in a similar conversion (37\%), but a drop in selectivity. No gluconic acid was observed, with $\mathrm{C} 2-\mathrm{C} 5$ aldoses and $\mathrm{CO}_{2}$ being the only products due to partial and total mineralization. However, excitingly, the authors demonstrated that this photocatalytic reaction can be carried out under natural cloudy day light in Liverpool (UK). 
Table 3. Effect of various parameters for glucose photocatalytic conversion with $\mathrm{TiO}_{2}$ [29].

\begin{tabular}{ccccccc}
\hline $\begin{array}{c}\text { [Glucose] } \\
(\mathbf{m M})\end{array}$ & $\begin{array}{c}\text { Light } \\
\text { Source }\end{array}$ & $\begin{array}{c}\text { Conv. } \\
\mathbf{( \% )}\end{array}$ & $\begin{array}{c}\text { Gluconic Acid } \\
\text { Selectivity (\%) }\end{array}$ & $\begin{array}{c}\text { C2-C5 } \\
\text { Aldoses } \mathbf{( \% )}\end{array}$ & $\begin{array}{c}\text { Specific Activity } \\
\left(\mathbf{m m o l} \cdot \mathbf{g}^{-\mathbf{1}} \cdot \mathbf{h}^{-\mathbf{1}} \mathbf{)}\right.\end{array}$ & $\begin{array}{c}\text { Mass } \\
\text { Balance (\%) }\end{array}$ \\
\hline 2.8 & visible & 42 & 7 & 93 & 21 & 90 \\
10 & visible & 10 & 10 & 90 & 18 & 100 \\
20 & visible & 5 & 12 & 88 & 19 & 100 \\
2.8 & UVA & 37 & 0 & 100 & 18 & 96 \\
10 & UVA & 15 & 6 & 94 & 21 & 99 \\
20 & UVA & 6 & 7 & 93 & 22 & 96 \\
\hline
\end{tabular}

Reaction conditions: $240 \mathrm{~min}$ illumination time, $14 \mathrm{mg}$ of catalysts $\left(1 \mathrm{~g} \cdot \mathrm{L}^{-1}\right)$.

Nevertheless, these three examples illustrate the limited selectivity and efficiency of an unmodified $\mathrm{TiO}_{2}$ photocatalyst for the photo-conversion of free sugars into corresponding derivative acids (gluconic or glucaric acid). The use of visible light to induce such a reaction is not obvious for $\mathrm{TiO}_{2}$-photocatalysts and the low selectivity is accentuated in aqueous medium due to the formation of highly reactive oxygen species [30].

To overcome these issues, one approach is the aliovalent doping of $\mathrm{TiO}_{2}$ with transition metal elements. Among the different transition metals, $\mathrm{Fe}^{3+}$ appears to be an excellent candidate owing to its important implication in redox reactions, low price, wide availability, and nontoxic nature. The interest in $\mathrm{Fe}^{3+}$ also stems from its ability to substantially modify the opto-electronic properties of anatase $\mathrm{TiO}_{2}$ and its comparable ionic radii rather than $\mathrm{Ti}^{4+}\left(\mathrm{r}_{(\mathrm{Fe}}{ }^{3+}\right)=0.645 \AA$ vs. $\left.\left.\mathrm{r}_{\left(\mathrm{Ti}^{2+}\right.}{ }^{4+}\right)=0.605 \AA\right)$ [31]. The introduction of $\mathrm{Fe}^{3+}$ into the lattice creates crystallographic and electronic point defects which narrow the optical bandgap down to $2.3 \mathrm{eV}(\lambda<540 \mathrm{~nm})$ [32]. Iron preferentially substitutes with the titanium into its site. The extra hole charge is compensated for by the formation of a half oxygen vacancy. Following this line, Colmenares et al. proposed the use of Fe-doped $\mathrm{TiO}_{2} \mathrm{immobilized} \mathrm{on}$ silica $\left(\mathrm{Fe}-\mathrm{TiO}_{2} / \mathrm{SiO}_{2}\right)$ or zeolite $\left(\mathrm{Fe}-\mathrm{TiO}_{2} / \mathrm{Ze}\right)$ for glucose photo-oxidation [33]. The photocatalysts were prepared following an optimized wet impregnation method assisted by ultrasonic irradiation. As expected, doping with $\mathrm{Fe}^{3+}$ led to the extension of the photocatalyst absorption band towards the visible region $\left(\lambda=457\right.$ and $470 \mathrm{~nm}$ for $\mathrm{Fe}-\mathrm{TiO}_{2} / \mathrm{Ze}$ and $\mathrm{Fe}-\mathrm{TiO}_{2} / \mathrm{SiO}_{2}$ respectively, compared to 379 and $375 \mathrm{~nm}$ for the undoped corresponding catalysts). This red-shift of absorption is explained by the creation of new energy levels corresponding to the $\mathrm{Fe}^{3+}$ ions in the band gap of $\mathrm{TiO}_{2}$. On other hand, the addition of $\mathrm{Fe}^{3+}$ had no significant effect on crystal phase (anatase) and crystallite size (ca. 12-13 nm and 5-6 nm for zeolite- and silica-supported $\mathrm{TiO}_{2}$, respectively). Both $\mathrm{Fe}-\mathrm{TiO}_{2} / \mathrm{SiO}_{2}$ and $\mathrm{Fe}-\mathrm{TiO}_{2} / \mathrm{Ze}$ were found to be photo-active, with the latter being the most selective towards glucaric and gluconic acids, leading, in optimized conditions, to a selectivity of $94 \%$ after $20 \mathrm{~min}$ of illumination using a $125 \mathrm{~W}$ Hg lamp. Nevertheless, the conversion yield remained too low for application since the authors achieved only $7 \%$. Colmenares et al. replaced $\mathrm{Fe}^{3+}$ by $\mathrm{Cr}^{3+}$ without improvement in either selectivity $(87 \%)$ or conversion yield $(7 \%)$, rigorously using the same experimental conditions (Table 4) [34]. Textural, structural, and optical features were of the same order of magnitude as using $\mathrm{Fe}^{3+}$ doping. Currently, the aliovalent doping of the anatase $\mathrm{TiO}_{2}$ with transition metals has not allowed the enhancement of the photo-conversion yield of glucose into gluconic and/or glucaric acids, despite a bandgap narrowing. This tends to suggest that until the experiments lead so far on the topic of aliovalent doping, the improved light absorption capability by the bandgap reduction will likely be compensated for by an enhancement of charge recombination without charge transfer induced by the introduction of donor states below the conduction band. 
Table 4. Effects of solvent composition on glucose conversion and selectivity towards glucaric/gluconic acids using $\mathrm{TiO}_{2}$ doped with $\mathrm{Fe}^{3+}$ or $\mathrm{Cr}^{3+}$ supported on $\mathrm{Ze} \mathrm{developed} \mathrm{by} \mathrm{Colmenares} \mathrm{et} \mathrm{al.} \mathrm{[33,34].}$

\begin{tabular}{|c|c|c|c|c|c|c|}
\hline \multirow{3}{*}{ Photocatalyst } & \multicolumn{6}{|c|}{ Solvent Composition } \\
\hline & \multicolumn{2}{|c|}{$10 \% \mathrm{H}_{2} \mathrm{O} / 90 \% \mathrm{CH}_{3} \mathrm{CN}$} & \multicolumn{2}{|c|}{$50 \% \mathrm{H}_{2} \mathrm{O} / 50 \% \mathrm{CH}_{3} \mathrm{CN}$} & \multicolumn{2}{|c|}{$100 \% \mathrm{H}_{2} \mathrm{O}$} \\
\hline & $\begin{array}{c}\text { Conversion } \\
{[\%]}\end{array}$ & $\begin{array}{c}\sum \text { Selectivity } \\
{[\%]}\end{array}$ & $\begin{array}{c}\text { Conversion } \\
{[\%]}\end{array}$ & $\begin{array}{c}\sum \text { Selectivity } \\
{[\%]}\end{array}$ & $\begin{array}{c}\text { Conversion } \\
{[\%]}\end{array}$ & $\begin{array}{c}\sum \text { Selectivity } \\
{[\%]}\end{array}$ \\
\hline $\begin{array}{c}\mathrm{Fe}-\mathrm{TiO}_{2} / \mathrm{Ze} \\
20 \text { min illumination }\end{array}$ & 19.2 & 61.5 & 7.2 & 94.3 & 8.3 & 0 \\
\hline $\begin{array}{c}\mathrm{Cr}-\mathrm{TiO}_{2} / \mathrm{Ze} \\
20 \text { min illumination }\end{array}$ & 10 & 71 & 7 & 87 & 5 & 0 \\
\hline $\begin{array}{c}\mathrm{Fe}-\mathrm{TiO}_{2} / \mathrm{Ze} \\
90 \text { min illumination }\end{array}$ & 60.4 & 41.1 & 19.6 & 57.5 & 13 & 0 \\
\hline $\begin{array}{c}\mathrm{Cr}-\mathrm{TiO}_{2} / \mathrm{Ze} \\
90 \text { min illumination }\end{array}$ & 24 & 46 & 8 & 77 & 6 & 0 \\
\hline
\end{tabular}

To overcome these issues, another approach was led by Bellardita et al., who proposed the design of heteropolyacid (HPA)- $\mathrm{TiO}_{2}$ composites [35]. Two molecules were coupled at the $\mathrm{TiO}_{2}$ surface; namely commercial Keggin heteropolyacid $\left(\mathrm{H}_{3} \mathrm{PW}_{12} \mathrm{O}_{40}\right)$ and home-prepared $\mathrm{K}_{7} \mathrm{PW}_{11} \mathrm{O}_{39}$ salt. The immobilization of such heteropolyacids was motivated by their ability to efficiently absorb UV light. This property leads to the formation of the charge transfer excited state HPA*, which has a better oxidizing power than the HPA ground state. The immobilization of $\mathrm{HPA}$ upon $\mathrm{TiO}_{2}$ enhances this property owing to the possible injection of photo-generated electrons from $\mathrm{TiO}_{2} \mathrm{CB}$ into HPA. The two HPA were anchored upon $\mathrm{TiO}_{2}$ by a solvothermal approach on one hand, and by impregnation upon commercial P25 on the other hand. The reaction was performed using aqueous glucose solution, irradiated with a $125 \mathrm{~W}$ medium pressure $\mathrm{Hg}$ lamp providing UV irradiation. Gluconic acid, but also arabinose, erythrose, and formic acids, were observed whatever the catalyst used $\left(\mathrm{HPA} / \mathrm{TiO}_{2}\right.$ or bare $\mathrm{TiO}_{2}$ ). Fructose, resulting from the isomerization of glucose, and some traces of glucaric acid and glyceraldehyde, were also observed for some runs. Both the selectivity and distribution of intermediate products were dependent on the photocatalyst used.

The addition of plasmonic nanoparticles such as $\mathrm{Ag}, \mathrm{Pt}$, and $\mathrm{Au}$ nanoparticles upon the $\mathrm{TiO}_{2}$ surface was shown to extend light harvesting of the photocatalyst to the visible portion of light thanks to the concomitant surface plasmon resonance effect (SPR) [9]. In addition, the contact with an adequate semi-conductor prolongs the excited-state lifetime of the metal as a result of the improved charge separation process, thus leaving a longer-lived oxidative hole in the metal to quantitatively onset the photo-oxidation process. In 2016, Da Vià et al. reported the photocatalytic oxidation of glucose using Ag nanoparticles on $\mathrm{TiO}_{2}$ under visible light conditions [36]. These conditions nearly suppressed the mineralization pathway. $\mathrm{Ag} / \mathrm{TiO}_{2}$ photocatalysts were prepared by a deposition-precipitation method. This procedure gives Ag nanoparticles with a size of approximately $4 \mathrm{~nm}$. This size is well-suited to obtain the plasmonic effect. Indeed, it has been reported that the plasmonic effect is negligible for NPs with a size smaller than $2 \mathrm{~nm}$ and that size differences between N"Ps $>5 \mathrm{~nm}$ have a negligible effect on their absorbance wavelength [37-39]. The authors demonstrated that mineralization is a function of the light conditions. Under UV conditions, the mineralization of glucose takes place, inducing selectivity fading. A series of $\mathrm{Ag} / \mathrm{TiO}_{2}$ catalysts with different loadings of $\mathrm{Ag}$ from 0.5 to $1.5 \mathrm{wt}$. \% conditions were investigated in an $\mathrm{H}_{2} \mathrm{O} / \mathrm{CH}_{3} \mathrm{CN}(1: 1)$ solvent mixture using air as the oxidant. Interestingly, the $0.5 \mathrm{wt}$. $\% \mathrm{Ag} / \mathrm{TiO}_{2}$ photocatalyst is the most selective, leading to $20 \%$ selectivity to gluconic acid after $2 \mathrm{~h}$ of illumination. The remaining $80 \%$ of the other products corresponds to organic degradation byproducts, such as arabinose, erythrose, glyceraldehyde, and formic acid. A mechanism was proposed based on the Ruff degradation reaction and $\alpha$-scission process to explain the presence of gluconic acid, smaller carbohydrates (arabinose, erythrose, glyceraldehyde), and formic 
acid (Scheme 3). The photocatalysts were reusable without any loss of activity. Nevertheless, regardless of all the photo-catalysts developed, the conversion yield could not exceed $7 \%$.

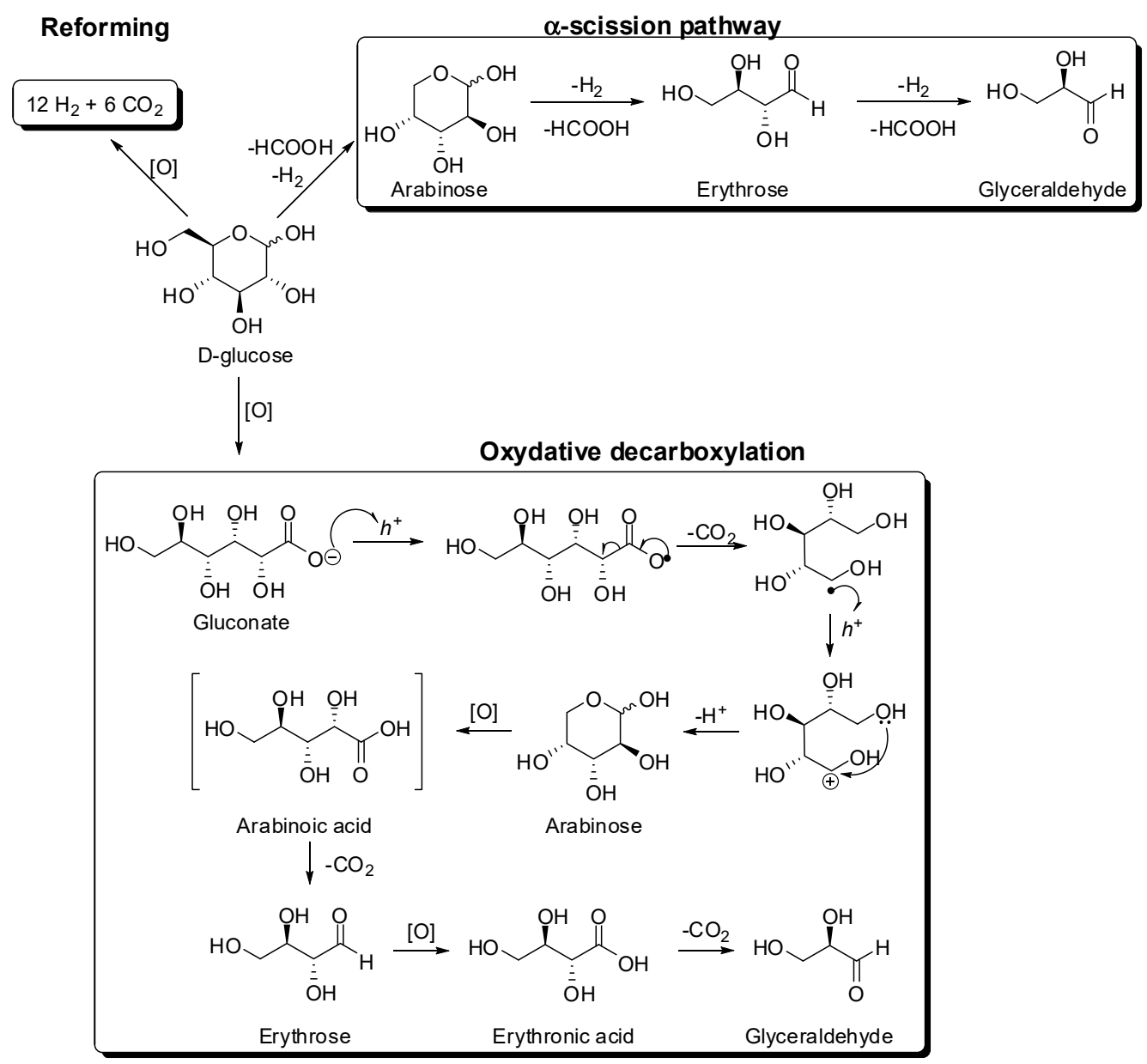

Scheme 3. Proposed mechanism accounting for the photocatalytic conversion of glucose under visible and UVA light illumination proposed by Da Vià et al. [36]. The pathway includes the $\alpha$-scission hypothesis of Chong et al. [40] and Ruff degradation [41].

Gold has been considered inert for a long time. However, since the discovery of its unique optical and electronic properties at the nanoscale, its utilization for photocatalysis applications has grasped considerable interest owing to a strong and broad plasmonic band at $c a .525 \mathrm{~nm}$. The introduction of gold NPs led to successful photocatalytic reactions under visible-light $[10,11]$. Recently, Zhou et al. studied the selective photo-oxidation of biomass derivatives by using an $\mathrm{Au} / \mathrm{TiO}_{2}$ photocatalyst and air as the oxidant [42]. Two simple sugars (glucose and xylose) and furfural derivatives were used. Glucose was totally and selectively oxidized into its corresponding aldonate derivatives after $4 \mathrm{~h}$ of illumination under both visible and UV light, at $30{ }^{\circ} \mathrm{C}$ ( $94 \%$ and $99 \%$ of selectivity, respectively). The authors demonstrated that the photocatalyst can be reused at least four times without any significant decrease in both photo-activity and selectivity. Similar results were obtained for xylose in $6 \mathrm{~h}$ (quantitative conversion and $96 \%$ of selectivity under UV light, $98 \%$ under visible light). In contrast to previous experimental procedures, the reaction was herein carried out in aqueous alkaline conditions $\left(\mathrm{Na}_{2} \mathrm{CO}_{3}\right)$. The authors argued that the excellent selectivity was preserved by the base, which plays a crucial role in the photocatalytic reaction. Indeed, under visible light, the base acts as an effective promoter, whereas under UV light, it serves as a sacrificial agent to inhibit the highly oxidizing oxygen species, as evidenced by electron paramagnetic resonance (EPR) experiments. Even if the lamp flux and spectrum were not standardized, a high power of $300 \mathrm{~mW} / \mathrm{cm}^{2}$ was used, and it is worth noting that this work 
constitutes the first example of a complete and selective conversion of xylose and glucose. Depending on whether UV or visible irradiation is used, two different charge separation mechanisms are proposed (Figure 3). Under visible light (part A, Figure 3), a photo-excited electron from Au NPs generated by the surface plasmon resonance effect is injected into $\mathrm{TiO}_{2}{ }^{\prime}$ s conduction band. This electron then reduces molecular oxygen $\left(\mathrm{O}_{2}\right)$ into its radical counterpart $\left(\mathrm{O}_{2} \cdot\right)$, which ensures alcohol or aldehyde transformation into carboxylic acid. For UV irradiation (part B; Figure 3), the photo-excited electron transits in $\mathrm{TiO}_{2}$ from the VB to the CB. It is then transferred towards Au NPs, leading to the same $\mathrm{O}_{2}$. reactive species responsible for the oxidation.

(A)

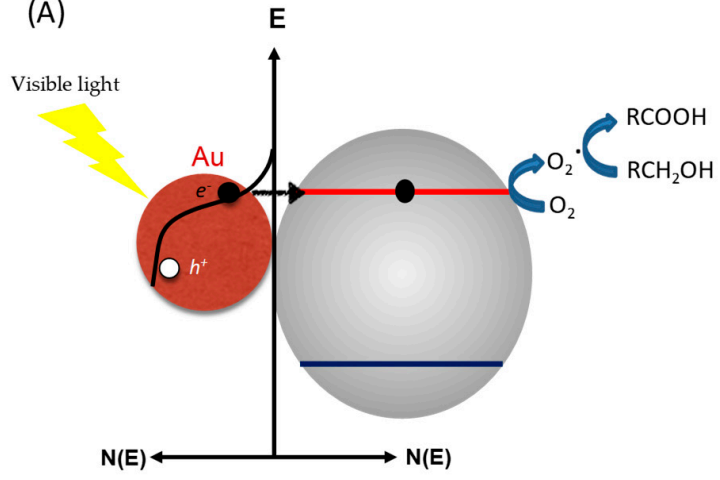

(B)

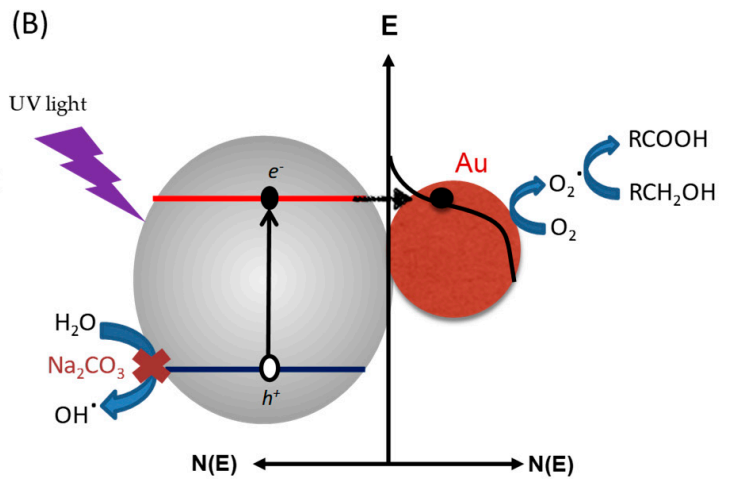

Figure 3. Proposed reaction mechanism for the photo-induced biomass derivatives' transformation by using an $\mathrm{Au} / \mathrm{TiO}_{2}$ photocatalyst under visible (A) and UV (B) irradiation proposed by Zhou et al. [42].

Simultaneously to this work, Omri et al. reported an efficient and very fast procedure quantitatively and selectively allowing sodium aldonates to be obtained in $10 \mathrm{~min}$ [43]. A significant step forward has been achieved with an experimental procedure carried out under realistic white light illumination conditions at $20^{\circ} \mathrm{C}$, namely standardized Air Mass $1.5 \mathrm{G}$ conditions typically used for photovoltaic characterization $\left(100 \mathrm{~mW} / \mathrm{cm}^{2}\right)$. The reaction initially targeted selective glucose oxidation by means of three photocatalysts: $\mathrm{Au} / \mathrm{TiO}_{2}, \mathrm{Au} / \mathrm{Al}_{2} \mathrm{O}_{3}$, and $\mathrm{Au} / \mathrm{CeO}_{2}$, using hydrogen peroxide as the oxidant under alkaline conditions. These photocatalysts were obtained by the deposition-precipitation of gold salts on the support surface. An illustration of $\mathrm{Au} / \mathrm{CeO}_{2}$ is given in Figure 4. The HR-TEM images clearly highlight gold nanoparticles of a $\sim 2.5 \mathrm{~nm}$-size loaded on the surface of the $\mathrm{CeO}_{2}$ nanoparticles.

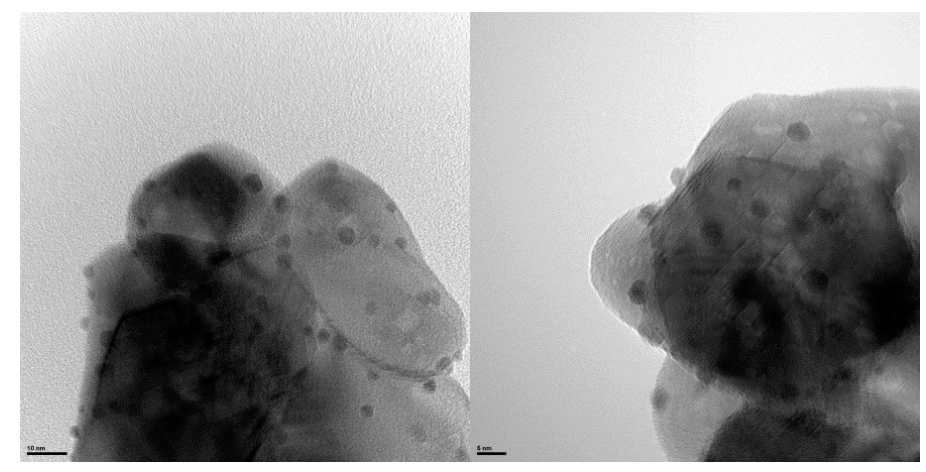

Figure 4. HR-TEM images of $\mathrm{Au} / \mathrm{CeO}_{2}$ photocatalysts obtained from M. Omri et al. [43].

Compared to the two other photocatalysts, the $\mathrm{Au} / \mathrm{CeO}_{2}$ showed the best performances, with a turn-over frequency (TOF) around $750,000 \mathrm{~h}^{-1}$. The recyclability of the photocatalyst has also been demonstrated since this latter can be reused up to five times without any loss of photocatalytic activity in terms of both conversion yield and selectivity. No textural modifications of the photocatalyst were observed on the basis of TEM (transmission electronic microscopy), AAS 
(atomic absorption spectroscopy), XPS (X-ray photoelectron spectroscopy), and XRD (X-ray diffraction) analyses. Interestingly, this methodology was shown to be efficient and versatile to a variety of carbohydrates, including mono- and oligosaccharides, while preserving the quantitative photocatalytic yield ( $>99 \%$ ) and selectivity ( $>95 \%$ ) without degradation of the glycosidic linkage (Figure 5$)$. This work stands as the first example of an efficient photo-driven oxidation reaction of oligo-saccharides without any interglycosidic linkage rupture, which is well-established in the literature to be case sensitive.

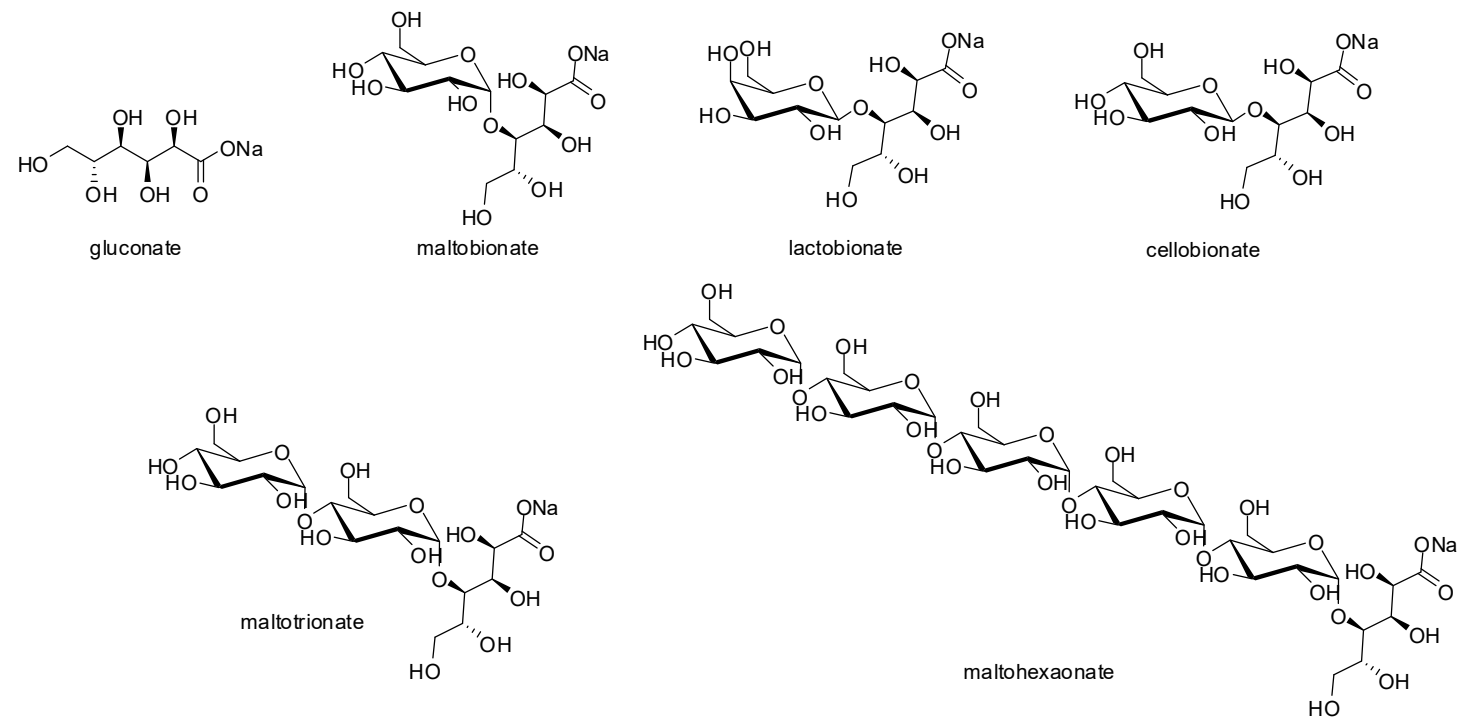

Figure 5. Products obtained by photocatalytic selective oxidation of various oligosaccharides after 10 min of standardized sunlight illumination (A.M.1.5G) from M. Omri et al. [43].

For the $\mathrm{Au} / \mathrm{CeO}_{2}$ photocatalyst under visible light, a slightly different reaction mechanism is proposed compared to Zhou's study. Under visible illumination, an excited electron (hot $\mathrm{e}^{-}$) is injected from the gold nanoparticle into the semiconductor $\mathrm{CB}$, leading to the creation of a long-lived hole in the gold nanoparticles (hot $\mathrm{h}^{+}$) (Figure 6). The selectivity is explained on the basis of adsorption through the anomeric position of sugar, hole capture from gold to the carbon C-1 of the carbohydrate, and then desorption of the sugar without any means of radical intermediates. This reaction requires $\mathrm{H}_{2} \mathrm{O}_{2}$ along with carbohydrate in solution. The hydrogen peroxide plays two roles: an electron scavenger to enhance hole reactivity towards sugar oxidation [44] and a UV filter to avoid excessive radical formation (e.g., $\mathrm{OH}^{-} \cdot$ ) induced by hole transfer from the $\mathrm{TiO}_{2}$ bandgap excitation.

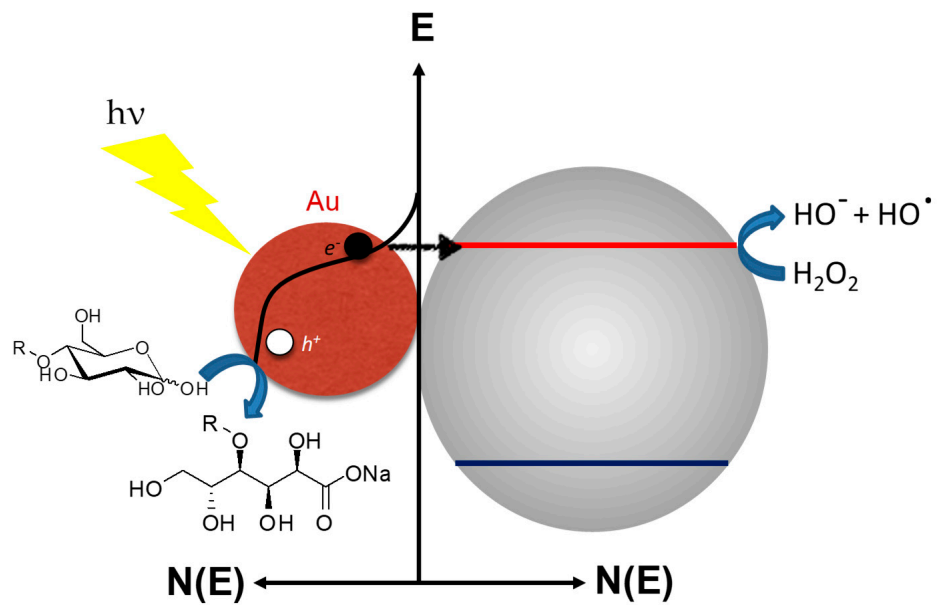

Figure 6. Proposed reaction mechanism of selective oxidation of free carbohydrates by using $\mathrm{Au} / \mathrm{MO}_{\mathrm{x}}$ under standard A.M.1.5G conditions from Omri et al. [43]. 
These two studies of Zhou et al. and Omri et al. lay the foundation towards the efficient oxidation of free mono and oligosaccharides under visible light conditions by means of gold-based photocatalysts. These procedures are very selective since only the anomeric position of free sugars is concerned in the photocatalytic process. In these regioselective reactions, the sugar backbone is preserved, but the degradation of free sugars can also lead to valuable high-added value products.

\section{Degradation of Free Sugars into High-Added Value Products}

Photocatalytic transformations for the conversion of free sugars, leading to the degradation or shortening of the sugar backbone, can lead to a wide variety of organic chemicals, as well as mineral compounds, with the most studied one being molecular hydrogen. This section is divided into two sections, based on the nature of the desired products: organic or inorganic.

\subsection{Degradation of Free Sugars into Organic Compounds}

The photo-degradation of sugars into organic molecules, such as smaller sugars (arabinose or erythrose for instance), ethanol, acetaldehyde, formic and acetic acids, etc., has been explored under UV or visible light. Once again, $\mathrm{TiO}_{2}$ (modified or pristine) is the most used photocatalyst. In 2014, Chong et al. developed a procedure for the direct conversion of glucose to arabinose and erythrose (Table 5) [40]. For this, a series of $\mathrm{TiO}_{2}$-based photo-catalysts were synthesized, in which the surface was modified by either Rh, Pt, or Pd (0.2 wt \%) NPs; or Cu and Ni NPs $(1.0 \mathrm{wt} \%)$, via a photo-deposition method. The photocatalytic transformation was performed in water using a non-filtered $300 \mathrm{~W}$ top-irradiated xenon lamp as the light source. $\mathrm{Rh} / \mathrm{TiO}_{2}$ was found to be the most efficient photocatalyst for the conversion of glucose. In order to compare the intrinsic activity of the catalyst, different semiconductors, namely $\mathrm{TiO}_{2}-\mathrm{A}$ (anatase), $\mathrm{TiO}_{2}-\mathrm{R}$ (rutile), and commercial $\mathrm{P} 25$ with a different specific area, were investigated. Amongst the different metals explored, the $\mathrm{Rh} / \mathrm{TiO}_{2}-\mathrm{R}$ photocatalyst provided the best selectivity $(>91 \%)$ towards arabinose and erythrose at $65 \%$ conversion (Table 5). EPR analysis suggests that the selectivity was dependent on the reactive HO. radicals produced on the anatase surface during the water oxidation. This gave rise to a loss of selectivity. By contrast, mild peroxyl species generated in the rutile phase can partially cleave $\mathrm{C}-\mathrm{C}$ bonds. Polyols, such as sorbitol, have also been used as substrates, leading to a mixture of different hydrocarbonated compounds with $1,2,3,4,5$, and 6 carbons being obtained.

Table 5. Direct conversion of glucose to arabinose and erythrose using $\mathrm{TiO}_{2}-\mathrm{R}$-loaded catalysts developed by Chong et al. [40].

\begin{tabular}{cccccc}
\hline \multirow{2}{*}{ Co-catalyst } & \multirow{2}{*}{$\begin{array}{c}\text { Reaction Time } \\
\text { (h) }\end{array}$} & $\begin{array}{c}\text { Conversion } \\
\text { (\%) }\end{array}$ & \multicolumn{2}{c}{ Selectivity (\%) } & \multirow{2}{*}{$\sum$ Selec [\%] } \\
\cline { 4 - 5 } None & 4 & Trace & - & - & - \\
$\mathrm{Pt}$ & 4 & 35.9 & 78.6 & 21 & 99.4 \\
& 4 & 47 & 74.7 & 20.6 & 95.3 \\
$\mathrm{Rh}$ & 6 & 61.3 & 68.9 & 23.6 & 92.5 \\
$\mathrm{Ni}$ & 6 & 27 & 88.6 & 7.5 & 96.1 \\
$\mathrm{Cu}$ & 6 & 40.7 & 85.9 & 12.5 & 98.4 \\
$\mathrm{Pd}$ & 6 & 59.1 & 72.3 & 24.7 & 97 \\
\hline
\end{tabular}

Reaction conditions: catalyst $0.1 \mathrm{~g}$; co-catalyst, $0.2 \mathrm{wt} \% \mathrm{Pt}, \mathrm{Rh}, \mathrm{Pd}: 1 \mathrm{Wt} \% \mathrm{Cu}, \mathrm{Ni} ; 0.0125 \mathrm{mmol} \cdot \mathrm{L}^{-1}$ aqueous glucose solution, $100 \mathrm{~mL}$; light source: xenon lamp (300 W), $288 \mathrm{~K}$.

Cellulose is the most abundant inedible polysaccharide on Earth. Its conversion is therefore becoming increasingly attractive for the production of value-added chemicals from biomass. Wang et al. envisioned, for the first time, the conversion of cellulose into valuable chemicals under visible light (glucose, 5-hydroxymethylfurfural (HMF) and levulinic acid (LeA)) [45]. The photocatalytic conversion was carried out by using a new plasmonic nanostructure made of $\mathrm{TiO}_{2}$ nanofibers (T) supporting H-form Y-zeolites (HY) decorated by Au-NPs (Au-HYT). The immobilization of such nanozeolites on 
ultrathin nanofibers was argued to enhance the catalyst selectivity by providing the reactants with access to active sides inside channels. The loading of plasmonic metal nanoparticles on a solid catalyst enhanced both the photocatalytic activity and selectivity through the SPR effect, as aforementioned. After $16 \mathrm{~h}$ of continuous illumination at $140{ }^{\circ} \mathrm{C}$, Au-HYT showed the best performances, with a total photoconversion of 59\% compared to non-loaded metal catalysts (HYT, YT, HY, and HT) and Au-loaded zeolite $\mathrm{Y}$ supported on $\mathrm{TiO}_{2}$ (Au-YT) (Table 6). Interestingly, no levulinic acid was produced when using Au-HYT. The influence of different reaction parameters, such as reaction temperature, light power, and wavelength, was studied. Catalyst acidity and the SPR effect of Au-NPs under visible light were shown to play a key role in the mechanism. The authors proposed a reaction mechanism based on acidic conditions enhanced by the polarized electrical fields of zeolites due to the SPR effect of Au.

Table 6. Conversion of cellulose using various catalysts, described by Wang et al. [45].

\begin{tabular}{ccccccc}
\hline \multirow{2}{*}{ Catalyst } & \multicolumn{3}{c}{ Light on } & \multicolumn{3}{c}{ Light-off } \\
\cline { 2 - 7 } & Glucose & HMF & Total & Glucose & HMF & Total \\
\hline HYT & 14 & 10.1 & 24.1 & 11.1 & 7.5 & 18.6 \\
YT & 24.9 & 5.7 & 30.6 & 19.6 & 4.6 & 24.2 \\
HY & 20.2 & 19.1 & 39.3 & 18.9 & 17.1 & 36 \\
HT & 14.9 & 5.7 & 20.6 & 10.6 & 4.9 & 15.5 \\
Au-HYT & 48.1 & 10.6 & 58.7 & 15.5 & 0 & 15.5 \\
Au-YT & 30.2 & 2.6 & 32.6 & 10.2 & 0 & 10.2 \\
\hline
\end{tabular}

Reaction conditions: $50 \mathrm{mg}$ cellulose, $50 \mathrm{mg}$ catalyst, $500 \mathrm{mg}$ water, $4.5 \mathrm{~g}$ EMIMCl, $0.5 \mathrm{~W} \mathrm{~cm}{ }^{-2}$ visible light, $140{ }^{\circ} \mathrm{C}, 16 \mathrm{~h}$.

Recently, in order to develop an efficient synthesis of formic acid, which is known to be an excellent hydrogen-storage material, photocatalytic oxidation cleavage of glucose into formate was described using Degussa P25 $\mathrm{TiO}_{2}$ in slightly alkaline medium [46] The first experiments were performed in the presence and absence of $\mathrm{NaOH}$ for $3 \mathrm{~h}$ irradiation (125 W high-pressure $\mathrm{Hg}$ lamp). The results clearly showed an improvement of about eight times the conversion yield of glucose (79.6\%), with higher formate selectivity $(14.2 \%)$ in alkaline conditions. The control of the base quantity is reported to be crucial. Indeed, as suggested by the authors, alkaline medium promotes the generation of oxidative radicals, such as $\mathrm{O}_{2}{ }^{-}$and $\mathrm{OH}$, which assist glucose oxidation, in contrast to what has been previously proposed in the literature [42]. Moreover, alkaline medium can also change the affinity strength between $\mathrm{TiO}_{2}$ and formate ions, avoiding the mineralization of the latter (Table 7). The temperature also contributes to the photo-conversion of glucose. Decreasing the temperature to $25^{\circ} \mathrm{C}$ resulted in a decrease in lactic acid production, classically obtained when glucose is warmed at alkaline $\mathrm{pH}$ [47]. Optimal conditions, namely $25{ }^{\circ} \mathrm{C}$ and $9 \mathrm{~h}$ of irradiation, led to a total conversion of glucose, with a $35 \%$ selectivity towards formate.

Table 7. Conversion of glucose and formate selectivity, reported by Jin et al. [46].

\begin{tabular}{ccc}
\hline Additive & Glucose Conversion (\%) & Formate Selectivity (\%) \\
\hline- & Trace & 0 \\
$\mathrm{TiO}_{2}(10 \mathrm{mg})$ & 9.7 & 10.8 \\
$\mathrm{NaOH}(0.06 \mathrm{M})+\mathrm{TiO}_{2}(10 \mathrm{mg})$ & 11.8 & 0 \\
$\mathrm{NaOH}(0.06 \mathrm{M})+\mathrm{TiO}_{2}(10 \mathrm{mg})$ & 79.6 & 14.2 \\
\hline
\end{tabular}

Reaction conditions: $125 \mathrm{~W} \mathrm{Hg}$ lamp irradiation, $3 \mathrm{~h}$ at $50{ }^{\circ} \mathrm{C} .{ }^{*}$ without irradiation.

\subsection{Degradation of Free Sugars into Inorganic Chemicals}

\subsubsection{Mineralization}

Organic materials can undergo complete mineralization to $\mathrm{CO}_{2}$ and $\mathrm{H}_{2} \mathrm{O}$ in the presence of a photocatalyst under illumination. This property led to the consideration that photocatalysis can 
be a valuable method for water and air purification, and pollutant remediation. In some studies, sugars have been used as organic models. For example, in 2002, Amal et al. proposed Ag/ $\mathrm{TiO}_{2}$ photocatalysts for the mineralization of organic compounds, among which were sucrose, glucose, and fructose [48-50]. Compared to bare $\mathrm{TiO}_{2}$, the deposition of silver upon $\mathrm{TiO}_{2}$ enhanced the mineralization rate of glucose, fructose, and sucrose, when exposed to UV light, by a factor of 7.2, 8.0, and 5.7, respectively. The degradation mechanism was explained by the photo-induced hole transfer to the organic molecule, in which silver allows better charge separation and lower charge recombination. The same group then explored the mineralization of the same carbohydrates using $\mathrm{TiO}_{2}$ [51] or $\mathrm{Pt} / \mathrm{TiO}_{2}$ [52] photocatalyst, prepared by flame spray pyrolysis (FSP). The photocatalytic mineralization of sucrose, glucose, and fructose was studied under UV light $(\lambda \sim 355 \mathrm{~nm})$ in aqueous perchloric acid $(\mathrm{pH}=3.25)$. The reaction was monitored by conductivity measurements of released $\mathrm{CO}_{2}$. Based on the results reported in this study, the authors suggested an extension of the previous mechanism proposed by Vamathevan [49] First, under these conditions, the hydrolysis of sucrose into glucose and fructose is assisted by the capture of the hole $\left(\mathrm{h}^{+}\right)$, which attacks the two electron pairs of the glycosidic bond (Scheme 4). Secondly, holes attack the $\pi$ electron of oxygen, leading to the opening of the saccharidic rings and the consequent oxidation of the aldehyde functions into carboxylic acids. Finally, the adsorption of carboxylic acids onto the $\mathrm{TiO}_{2}$ surface promotes the decarboxylation. This study showed a better photoactivity of FSP-made $\mathrm{TiO}_{2}$ compared to the classical $\mathrm{P} 25 \mathrm{TiO}_{2}$ photocatalyst, owing to the higher surface area and more efficient interfacial charge transfer.

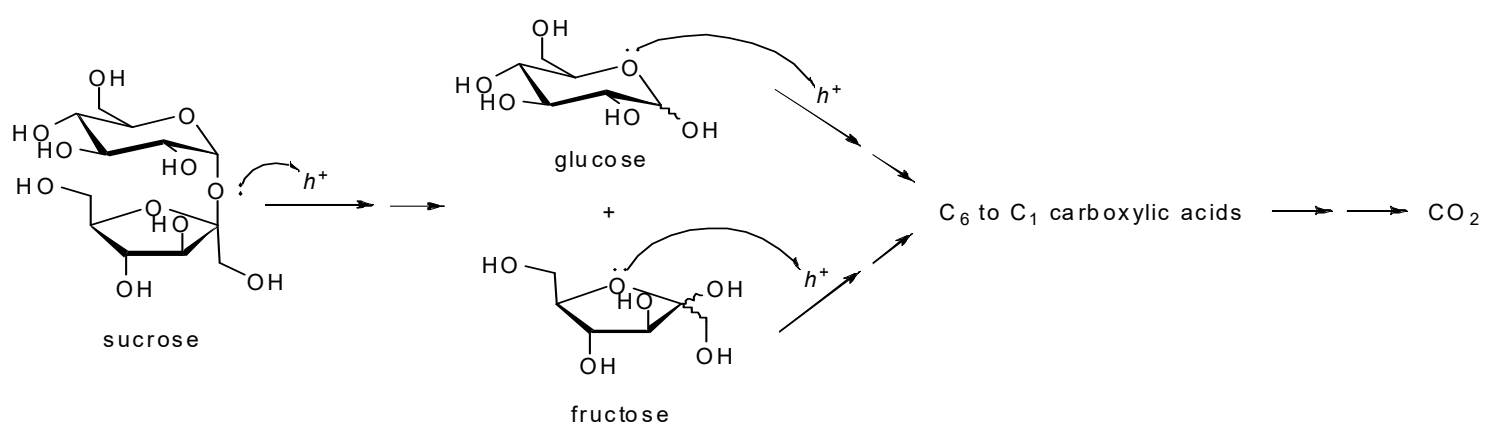

Scheme 4. Photocatalytic mineralization pathway of sucrose, glucose, and fructose proposed by Teoh et al. [51] and extended from Vamathevan et al. [49].

\subsubsection{Hydrogen Production}

Because of the serious concerns regarding the depletion of fossil resources and the consequent environmental issues, hydrogen production from renewable sources has attracted much interest as a clean energy resource. Among the various technologies to convert biomass into $\mathrm{H}_{2}$, heterogeneous water splitting by sunlight is considered as one of the most promising renewable routes since the pionnering work of Honda et al. [53]. As described in the introduction, light absorption of the photocatalyst affords promoting free electrons into the $\mathrm{CB}$ and oxidizing holes in the $\mathrm{VB}$, which can, in principle, lead to water photolysis at conditions where the optical bandgap is greater than $1.23 \mathrm{eV}$ and with accurate bands' alignement for proton reduction and water oxidation (Figure 7) [54]. Nevertheless, this process is not very efficient because of (i) the fast recombination between photoinduced carriers, (ii) the four electron process involved in water cleavage, and (iii) oxygen formation difficulties. The $\mathrm{H}_{2}$ yield can be improved by means of sacrificial electron donors, such as $\mathrm{Na}_{2} \mathrm{~S}, \mathrm{EDTA}$, or $\mathrm{NaSO}_{3}$, but scientists' interest has increasingly become focused on renewable, cheap, and easy-to-obtain resources, such as carbohydrates, since the pioneer work of Kawai and Sakata [55]. Again, glucose is the most studied carbohydrate as it can be easily extracted from renewable ressources available in great quantity worldwhile, such as starch or cellulose, but also from food industry waste. Glucose plays two roles in photocatalyzed hydrogen production. It can act as an electron donor, but also serves as a hydrogen source by a reforming reaction, which allows the supplementary production of hydrogen. 


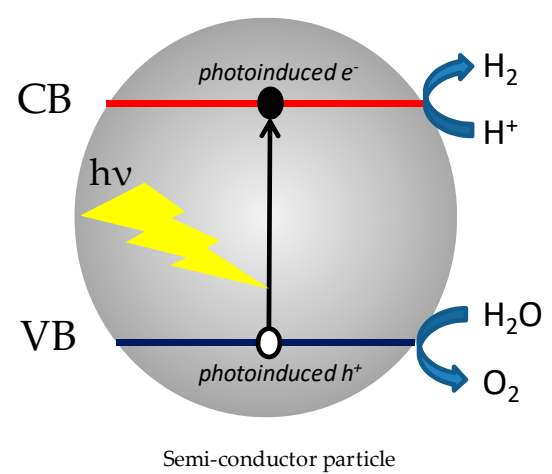

Figure 7. Principle of water splitting using semiconductor photocatalysts from Kudo et al. [54].

Most of the ongoing research on this topic implies the use of $\mathrm{TiO}_{2}$ and modified- $\mathrm{TiO}_{2}$ photocatalysts for $\mathrm{H}_{2}$ production from aqueous glucose solution. For the sake of clarity, the various $\mathrm{TiO}_{2}$-based materials used for hydrogen production from carbohydrates are listed in Table 8, with some of their characteristics. The light source and power are also reported, since these are of high importance in photoinduced processes.

As shown by $\mathrm{Fu}$ et al., bare $\mathrm{TiO}_{2}$ was almost inactive to produce $\mathrm{H}_{2}$, even under $\mathrm{UV}$ irradiation (125 W Hg lamp). However, the $\mathrm{H}_{2}$ yield can be improved by the deposition of various metals upon $\mathrm{TiO}_{2}$ [56]. The influence of carbohydrate nature, glucose concentration, nature of the loaded noble metal, $\mathrm{TiO}_{2}$ crystalline phase, and $\mathrm{pH}$ was investigated. Photolysis conditions are crucial since hydrogen production was inhibited in acidic conditions and in the presence of $\mathrm{O}_{2}$. The type of saccharidic skeleton affects the hydrogen evolution rate, ie., lower rates were observed when increasing the molecular weight of carbohydrates (glucose, sucrose, starch). As one could also expect, the type of deposited metal affects water photolysis $(\mathrm{Pd}>\mathrm{Pt}>\mathrm{Au} \approx \mathrm{Rh}>\mathrm{Ag} \approx \mathrm{Ru})$ and anatase shows better performances than rutile. The authors proposed a mechanism where $\mathrm{H}_{2}$ is produced by both water splitting and glucose reforming.

In 2016, Bellardita et al. explored the role of the crystalline phase of $\mathrm{TiO}_{2}$ (anatase, brookite, and rutile) of $\mathrm{Pt} / \mathrm{TiO}_{2}$ photocatalysts in $\mathrm{H}_{2}$ production [57]. Glucose conversion and $\mathrm{H}_{2}$ formation were enhanced using rutile and brookite polymorphs. This study also confirmed that the presence of $\mathrm{Pt}$ increases the degradation rate and the glucose mineralization degree.

The results of the study conducted by Fu [56] were also confirmed by Colmenares et al. [58], who showed that Pd and Pt metal NPs deposited on titania performed better for hydrogen production. Moreover, the authors reported that an $850{ }^{\circ} \mathrm{C}$ calcination process, which results in electronic transfer from titania to metal through the so-called strong metal support interaction (SMSI), was also beneficial. $\mathrm{A} \mathrm{Pt} / \mathrm{TiO}_{2}$ photocatalyst was also used to evaluate the effect of the anomeric form of D-glucose on hydrogen production under UV (Hg lamp) by Zhou et al. [59] Indeed, in aqueous solution, D-glucose is not an isolated product, but a mixture of three compounds, owing to the mutarotation at the C1 position and aldehyde-hemiacetal equilibrium: the linear glucose (generally $<5 \%$ ) and $\alpha / \beta$ anomers, for which the ratio is dependent on various parameters (Figure 8). The $\alpha$ anomer was shown to exhibit better photoactivity for hydrogen production than the $\alpha$ anomer, owing to its better adsorption upon the $\mathrm{TiO}_{2}$ surface.

Very recently, Sanwald et al. also described Rh-, Pd-, and Pt-decorated $\mathrm{TiO}_{2}$ for the UV photoreforming of aldoses in a study aimed at overcoming the rate-limiting reaction for hydrogen production [60]. This latter was identified as the accumulation of formate species, originating from the C-C $\alpha$-scission of aldoses (as described in Scheme 3). This tends to hinder the oxidation reaction sites, leading to enhanced $e^{-} / h^{+}$recombination. 
Table 8. $\mathrm{TiO}_{2}$-based catalysts used for $\mathrm{H}_{2}$-production from carbohydrates.

\begin{tabular}{|c|c|c|c|c|c|c|}
\hline \multirow{2}{*}{ Light Source } & \multicolumn{5}{|c|}{ Photocatalyst } & \multirow[b]{2}{*}{ Ref } \\
\hline & Name $^{a}$ & Phase $^{b}$ & $\operatorname{SSA}\left(\mathrm{m}^{2} / \mathrm{g}\right)$ & $\begin{array}{l}\text { Crystallite } \\
\text { Size }^{c}(\mathrm{~nm})\end{array}$ & $\begin{array}{c}\text { Energy } \\
\text { Bandgap }(\mathrm{eV})\end{array}$ & \\
\hline UV (Hg lamp 125 W) & $\begin{array}{c}\mathrm{TiO}_{2} \\
\mathrm{Pt} / \mathrm{TiO}_{2} 1 \mathrm{wt} \%\left(200{ }^{\circ} \mathrm{C}\right) \\
\mathrm{Pt} / \mathrm{TiO}_{2} 1 \mathrm{wt} \%\left(300{ }^{\circ} \mathrm{C}\right) \\
\mathrm{Pt} / \mathrm{TiO}_{2} 1 \mathrm{wt} \%\left(400{ }^{\circ} \mathrm{C}\right) \\
\mathrm{Pt} / \mathrm{TiO}_{2} 1 \mathrm{wt} \%\left(500{ }^{\circ} \mathrm{C}\right) \\
\mathrm{Pt} / \mathrm{TiO}_{2} 1 \mathrm{wt} \%\left(600{ }^{\circ} \mathrm{C}\right) \\
\mathrm{Pt} / \mathrm{TiO}_{2} 0.25 w \mathrm{wt} \% \\
\mathrm{Pt} / \mathrm{TiO}_{2} 0.5 \mathrm{wt} \% \\
\mathrm{Pt} / \mathrm{TiO}_{2} 0.75 \mathrm{wt} \% \\
\mathrm{Pt} / \mathrm{TiO}_{2} 1 \mathrm{wt} \% \\
\mathrm{Pt} / \mathrm{TiO}_{2} 2 \mathrm{wt} \% \\
\mathrm{Pt} / \mathrm{TiO}_{2} 3 \mathrm{wt} \% \\
\mathrm{Pd} / \mathrm{TiO}_{2} \\
\mathrm{Au} / \mathrm{TiO}_{2} \\
\mathrm{Rh} / \mathrm{TiO}_{2} \\
\mathrm{Ag} / \mathrm{TiO}_{2} \\
\mathrm{Ru} / \mathrm{TiO}_{2} \\
\mathrm{Rh} / \mathrm{TiO}_{2} \\
\mathrm{Rh} / \mathrm{TiO}_{2} \\
\mathrm{Rh} / \mathrm{TiO}_{2}\end{array}$ & $\begin{array}{c}- \\
A+B \\
A+B \\
A+B \\
A+B+R \\
R\end{array}$ & $\begin{array}{c}- \\
210.9 \\
137.4 \\
115.7 \\
50 \\
3.2\end{array}$ & - & - & [56] \\
\hline UV (Hg lamp $125 \mathrm{~W}$ ) & $\begin{array}{c}\text { P25 } \\
\text { Merck-TiO } \\
\text { BDH-TiO }_{2} \\
{\mathrm{HP}-\mathrm{TiO}_{2}} \\
\text { HP-brookite } \\
\text { HP-rutile } \\
\text { HP-S } \\
\text { HP-IP } \\
\text { Pt-P25 } \\
\text { Pt-BDH } \\
\text { Pt-HP-rutile } \\
\text { Pt-HP-brookite }\end{array}$ & $\begin{array}{c}A+R \\
A \\
A \\
A+R \\
B \\
R \\
A \\
A+R \\
A+R \\
A \\
R \\
B\end{array}$ & $\begin{array}{c}50 \\
10 \\
9 \\
185 \\
82 \\
87 \\
44 \\
73 \\
48 \\
10 \\
85 \\
80\end{array}$ & $\begin{array}{c}25(\mathrm{~A}), 33(\mathrm{R}) \\
60 \\
52 \\
4.6(\mathrm{~A}), 2.1(\mathrm{R}) \\
6.6 \\
3.5 \\
23.6 \\
19(\mathrm{~A}), 54(\mathrm{R}) \\
27(\mathrm{~A}), 31(\mathrm{R}) \\
49 \\
4 \\
7.2\end{array}$ & $\begin{array}{l}3.18 \\
3.18 \\
3.23 \\
3.03 \\
3.25 \\
3.03 \\
3.17 \\
2.97 \\
2.76 \\
3.21 \\
2.94 \\
3.21 \\
\end{array}$ & [57] \\
\hline UV (Hg lamp 125 W) & $\begin{array}{l}\mathrm{Pt} / \mathrm{TiO}_{2}\left(500^{\circ} \mathrm{C}, \mathrm{Air}\right) \\
\mathrm{Pt} / \mathrm{TiO}_{2}\left(500^{\circ} \mathrm{C}, \mathrm{H}_{2}\right) \\
\mathrm{Pt} / \mathrm{TiO}_{2}\left(850^{\circ} \mathrm{C}, \mathrm{Air}\right) \\
\mathrm{Pt} / \mathrm{TiO}_{2}\left(850^{\circ} \mathrm{C}, \mathrm{H}_{2}\right) \\
\mathrm{Pd} / \mathrm{TiO}_{2}\left(500^{\circ} \mathrm{C}, \mathrm{Air}\right. \\
\mathrm{Pd} / \mathrm{TiO}_{2}\left(500^{\circ} \mathrm{C}, \mathrm{H}_{2}\right) \\
\mathrm{Pd} / \mathrm{TiO}_{2}\left(850^{\circ} \mathrm{C}, \mathrm{Air}\right) \\
\mathrm{Pd} / \mathrm{TiO}_{2}\left(850^{\circ} \mathrm{C}, \mathrm{H}_{2}\right)\end{array}$ & $\begin{array}{c}\mathrm{A} \\
\mathrm{A} \\
\mathrm{R} \\
\mathrm{R} \\
\mathrm{A} \\
\mathrm{A} \\
\mathrm{R} \\
7: 93 \mathrm{~A} / \mathrm{R}\end{array}$ & $\begin{array}{c}57 \\
50 \\
6 \\
6 \\
75 \\
62 \\
5 \\
7 \\
\end{array}$ & $\begin{array}{c}21 \\
23 \\
77 \\
66 \\
18 \\
21 \\
81 \\
66(\mathrm{~A}), 116(\mathrm{R})\end{array}$ & - & [58] \\
\hline UV (Hg lamp $250 \mathrm{~W}$ ) & $\mathrm{Pt} / \mathrm{TiO}_{2}$ & A & $124 *$ & $20 *$ & - & [59] \\
\hline $\begin{array}{l}\text { UV (High power UV } \\
\text { LED, } 365 \mathrm{~nm} \text { ) }\end{array}$ & $\begin{array}{c}\mathrm{P} 25 \\
\mathrm{Rh} / \mathrm{TiO}_{2} \\
\mathrm{Pd} / \mathrm{TiO}_{2} \\
\mathrm{Pt} / \mathrm{TiO}_{2}\end{array}$ & - & $\begin{array}{l}53 \\
51 \\
47 \\
52\end{array}$ & - & $\begin{array}{l}3.1 \\
3.1 \\
3.1 \\
3.1\end{array}$ & [60] \\
\hline $\begin{array}{l}\text { UV (UV-LED strip } \\
(10 W, 375-380 \mathrm{~nm}))\end{array}$ & 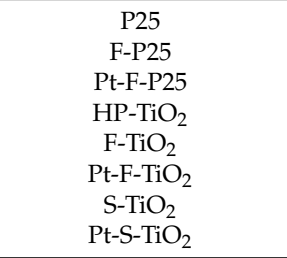 & $\begin{array}{c}80: 20 \mathrm{~A} / \mathrm{R} \\
90: 10 \mathrm{~A} / \mathrm{R} \\
\mathrm{A}\end{array}$ & $\begin{array}{l}51 \\
50 \\
47 \\
11 \\
51 \\
42 \\
58 \\
49\end{array}$ & $\begin{array}{l}22(\mathrm{~A}) \\
23(\mathrm{~A}) \\
21(\mathrm{~A}) \\
17(\mathrm{~A}) \\
24 \\
23 \\
20 \\
20\end{array}$ & $\begin{array}{c}3.23 \\
3.2 \\
3.2 \\
3.2 \\
3.21 \\
3.24 \\
3.2 \\
3.17 \\
\end{array}$ & [61] \\
\hline $\begin{array}{l}\mathrm{UV} \text { (Hg lamp } 125 \mathrm{~W}) \\
\text { solar/visible (100 W } \\
\text { halogen lamp using } \\
\text { filter solutions) }\end{array}$ & $\begin{array}{c}\text { untreated P25 } \\
\text { dispersed P25 } \\
\text { P25 } 40 \mathrm{kHz} 2 \mathrm{~h} \\
\text { Pt-P25 untreated } \\
\text { Pt-P25 } 40 \mathrm{kHz} 2 \mathrm{~h} \\
\text { Ag-P25 } 40 \mathrm{kHz} 2 \mathrm{~h} \\
\text { Pd-P25 } 40 \mathrm{kHz} 2 \mathrm{~h} \\
\text { Rh-P25 } 40 \mathrm{kHz} 2 \mathrm{~h}\end{array}$ & $\begin{array}{l}A+R \\
A+R \\
A+R \\
A+R \\
A+R \\
A+R \\
A+R \\
A+R\end{array}$ & $\begin{array}{c}55.6 \\
53.3 \\
55.8 \\
52.6 \\
52.5 \\
33.1 \\
47.8 \\
51\end{array}$ & $\begin{array}{l}24.8 \\
24.1 \\
28.5 \\
23.9 \\
26.7 \\
22.3 \\
31.2 \\
16.9\end{array}$ & $\begin{array}{c}3.18 \\
- \\
3.04 \\
- \\
3.14 \\
3.12 \\
3.08 \\
3.11\end{array}$ & [62] \\
\hline $\begin{array}{l}\text { Visible (Xe lamp } \\
300 \mathrm{~W})\end{array}$ & $\begin{array}{c}\mathrm{Pt} / \mathrm{TiO}_{2} \\
\mathrm{Pt} / \mathrm{B}-\mathrm{TiO}_{2} \\
\mathrm{Pt} / \mathrm{N}-\mathrm{TiO}_{2} \\
\mathrm{Pt} /(\mathrm{B}, \mathrm{N})-\mathrm{TiO}_{2}\end{array}$ & A & $\begin{array}{l}- \\
- \\
- \\
-\end{array}$ & $\begin{array}{c}30.3 \\
8.8 \\
23.6 \\
19.3\end{array}$ & $\begin{array}{l}3.09 \\
3.05 \\
2.95 \\
2.98\end{array}$ & [63] \\
\hline
\end{tabular}

${ }^{\text {a }} \mathrm{HP}$ refers to "home-prepared"; ${ }^{\mathrm{b}} \mathrm{A}, \mathrm{B}$, and R refer to anatase, brookite, and rutile, respectively; ${ }^{\mathrm{c}}$ determined using the Scherrer equation, ${ }^{*}$ characteristics of the supporting $\mathrm{TiO}_{2}$. 

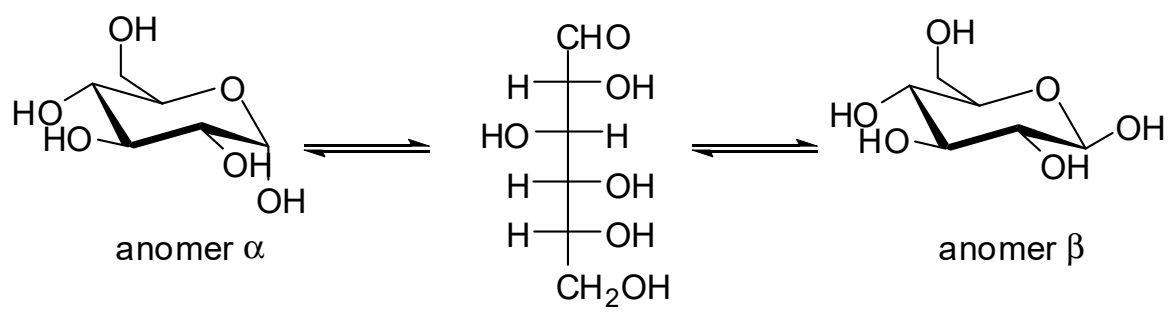

Figure 8. Mutarotation of D-glucose.

Beside modifying the surface of $\mathrm{TiO}_{2}$ by noble metals, aliovalent doping was also proposed to enhance $\mathrm{TiO}_{2}$ photocatalytic activity. Platinium-decorated F-doped-TiO $\mathrm{T}_{2}$ photocatalysts were successfully used for the photoreforming of glucose [61].

The use of non-titania materials was also reported: La doped alkali tantalate, which was already known as an efficient photocatalyst for water splitting, was employed in the presence of glucose under UV light, with good photocatalytic activity [64].

Nevertheless, all these experiments, dealing with the reforming of glucose using primarily $\mathrm{TiO}_{2}$-based photocatalysts, were systematically performed using an Hg lamp, for which the spectrum is primarily localized in the UV region and unrealistic with respect to a real application using direct sunlight. In 2017, Bellardita et al. demonstrated that metal-loaded $\mathrm{TiO}_{2}$ (Pd, Pt, $\mathrm{Ag}, \mathrm{Rh}$ ) prepared using an ultrasound-assisted procedure was active to produce $\mathrm{H}_{2}$ from glucose under visible light, with Pt being the most efficient, in agreement with previous reports [62] This synthetic procedure making use of ultrasound is argued to be at the origin of such activity. In agreement with cationic doping, anionic doping of $\mathrm{TiO}_{2}$ with $\mathrm{N}$ and $\mathrm{B}$ was also effective to shift the absortion band towards the visible range through a reduction in the band gaps from $3.09 \mathrm{eV}$ for the undoped one, to 3.05, 2.98, and $2.95 \mathrm{eV}$ for $\mathrm{B}-,(\mathrm{B}, \mathrm{N})-$, and $\mathrm{N}$-doped $\mathrm{TiO}_{2}$ [63]. As a result, hydrogen production under visible light was noticeably improved for platinum heteroatom-doped $\mathrm{TiO}_{2}$ compared to $\mathrm{Pt} / \mathrm{TiO}_{2}$. With the aim to use visible light, a new material paradigm is needed for glucose reforming. Other types of materials have been proposed, such as a solid solution of $\mathrm{Bi}_{\mathrm{x}} \mathrm{Y}_{1-\mathrm{x}} \mathrm{VO}_{4}$, and alternatively, p-type materials such as the cuprous oxide $\mathrm{Cu}_{2} \mathrm{O}$ [65] and $\mathrm{ZnS}$-coated $\mathrm{ZnIn}_{2} \mathrm{~S}_{4}$ [66].

\section{Conclusions}

The conversion of carbohydrates by making use of sunlight irradiation is a very exciting topic which shows very promising perspectives for obtaining high-added value products from biomass and following a sustainable procedure. Today, two kinds of photo-driven reactions are mainly studied: the oxidation of sugars, preserving the sugar backbone, and their degradation. Even if most studies have yielded mixtures of oxidation and scission products, recent advances in photocatalysts and experimental conditions have afforded not only a fast and quantitative conversion yield, but also a perfect selectivity into aldonic acid/aldonate salts by using visible light irradiation, paving the way for future successful developments. Nevertheless, there are still great efforts that need to be made in order to obtain the selective organic transformation of sugars before revolutionizing glycochemistry. Many organic transformations occurring on sugars should probably work more efficiently when combined with photo-activation and deserve the time to linger.

The use of sugars for hydrogen production is also a hot topic, without splitting water, which is a crucial resource for human kind. The last studies published on this topic are extremely encouraging in terms of reaching this target. This is a robust argument for the scientific community to pursue research in this direction.

Nevertheless, it should be emphasized that for real applications, discrepancies in the source of illumination can explain the difference of the results between different works. As in photovoltaics in which the measurement conditions require a standard light illumination procedure (Air Mass 1.5G conditions obtained by a filtered continuous Xe lamp), the field of photocatalysis should also 
be encouraged to use standardized illumination conditions in order to obtain realistic, comparable, and well-reproducible photolysis conditions for the selective oxidation of carbohydrates and/or hydrogen production.

Funding: This research received no external funding.

Acknowledgments: M.O. and S.G. deeply acknowledge their PhD financial support: Région Picardie and MESR, respectively.

Conflicts of Interest: The authors declare no conflict of interest.

\section{References}

1. Gallezot, P. Conversion of biomass to selected chemical products. Chem. Soc. Rev. 2012, 41, 1538-1558. [CrossRef] [PubMed]

2. Chatterjee, C.; Pong, F.; Sen, A. Chemical conversion pathways for carbohydrates. Green Chem. 2015, 17, 40-71. [CrossRef]

3. Haddad, J.; Vakulenko, S.; Mobashery, S. An antibiotic cloaked by its own resistance enzyme. J. Am. Chem. Soc. 1999, 121, 11922-11923. [CrossRef]

4. Choay, J.; Petitou, M.; Lormeau, J.C.; Sinay, P.; Casu, B.; Gatti, G. Structure-activity relationship in heparin: A synthetic pentasaccharide with high affinity for antithrombin III and eliciting high anti-factor Xa activity. Biochem. Biophys. Res. Commun. 1983, 116, 492-499. [CrossRef]

5. Saloranta, T.; Leino, R. Unprotected Carbohydrates as Starting Material in Chemical Synthesis: Not Just a Challenge but an Opportunity. Synlett 2015, 26, 421-425. [CrossRef]

6. Villadsen, K.; Martos-Maldonado, M.C.; Jensen, K.J.; Thygesen, M.B. Chemoselective reactions for the synthesis of glycoconjugates from unprotected carbohydrates. ChemBioChem 2017, 18, 574-612. [CrossRef] [PubMed]

7. Balzani, V.; Credi, A.; Venturi, M. Photochemical conversion of solar energy. ChemSusChem 2008, 1, 26-58. [CrossRef]

8. Schneider, J.; Matsuoka, M.; Takeuchi, M.; Zhang, J.; Horiuchi, Y.; Anpo, M.; Bahnemann, D.W. Understanding $\mathrm{TiO}_{2}$ photocatalysis: Mechanisms and materials. Chem. Rev. 2014, 114, 9919-9986. [CrossRef]

9. Park, H.; Kim, H.; Moon, G.; Choi, W. Photoinduced charge transfer processes in solar photocatalysis based on modified $\mathrm{TiO}_{2}$. Energy Environ. Sci. 2016, 9, 411-433. [CrossRef]

10. Wang, C.; Astruc, D. Nanogold plasmonic photocatalysis for organic synthesis and clean energy conversion. Chem. Soc. Rev. 2014, 43, 7188-7216. [CrossRef]

11. Xiao, M.; Jiang, R.; Wang, F.; Fang, C.; Wang, J.; Jimmy, C.Y. Plasmon-enhanced chemical reactions. J. Mater. Chem. A 2013, 1, 5790-5805. [CrossRef]

12. Friedmann, D.; Hakki, A.; Kim, H.; Choi, W.; Bahnemann, D. Heterogeneous photocatalytic organic synthesis: State-of-the-art and future perspectives. Green Chem. 2016, 18, 5391-5411. [CrossRef]

13. Shiraishi, Y.; Hirai, T. Selective organic transformations on titanium oxide-based photocatalysts. J. Photochem. Photobiol. C Photochem. Rev. 2008, 9, 157-170. [CrossRef]

14. Munir, S.; Dionysiou, D.D.; Khan, S.B.; Shah, S.M.; Adhikari, B.; Shah, A. Development of photocatalysts for selective and efficient organic transformations. J. Photochem. Photobiol. B Biol. 2015, 148, 209-222. [CrossRef] [PubMed]

15. Lu, H.; Yao, J. Recent Advances in Liquid-phase Heterogeneous Photocatalysis for Organic Synthesis by Selective Oxidation. Curr. Org. Chem. 2014, 18, 1365-1372. [CrossRef]

16. Lanterna, A.E.; Elhage, A.; Scaiano, J.C. Heterogeneous photocatalytic C-C coupling: Mechanism of plasmon-mediated reductive dimerization of benzyl bromides by supported gold nanoparticles. Catal. Sci. Technol. 2015, 5, 4336-4340. [CrossRef]

17. Zhao, J.; Zheng, Z.; Bottle, S.; Chen, C.; Huang, Y.; Sarina, S.; Chou, A.; Zhu, H. Factors influencing the photocatalytic hydroamination of alkynes with anilines catalyzed by supported gold nanoparticles under visible light irradiation. RSC Adv. 2016, 6, 31717-31725. [CrossRef]

18. Xiao, Q.; Sarina, S.; Waclawik, E.R.; Jia, J.; Chang, J.; Riches, J.D.; Wu, H.; Zheng, Z.; Zhu, H. Alloying gold with copper makes for a highly selective visible-light photocatalyst for the reduction of nitroaromatics to anilines. ACS Catal. 2016, 6, 1744-1753. [CrossRef] 
19. Colmenares, J.C.; Luque, R. Heterogeneous photocatalytic nanomaterials: Prospects and challenges in selective transformations of biomass-derived compounds. Chem. Soc. Rev. 2014, 43, 765-778. [CrossRef]

20. Colmenares, J.C.; Luque, R.; Campelo, J.M.; Colmenares, F.; Karpiński, Z.; Romero, A.A. Nanostructured photocatalysts and their applications in the photocatalytic transformation of lignocellulosic biomass: An overview. Materials 2009, 2, 2228-2258. [CrossRef]

21. Hustede, H.; Haberstroh, H.-J.; Schinzig, E. Ullmann's Encyclopedia of Industrial Chemistry; Wiley-VCH Verlag GmbH \& Co. KGaA: Weinheim, Germany, 2000.

22. Boussie, T.R.; Diamond, G.M.; Dias, E.; Murphy, V. Chemicals and Fuels from Bio-Based Building Blocks; Wiley-VCH Verlag GmbH \& Co. KGaA: Weinheim, Germany, 2016; pp. 151-172.

23. Skoog, E.; Shin, J.H.; Saez-Jimenez, V.; Mapelli, V.; Olsson, L. Biobased adipic acid-The challenge of developing the production host. Biotechnol. Adv. 2018, 36, 2248-2263. [CrossRef] [PubMed]

24. Colmenares, J.C.; Magdziarz, A.; Bielejewska, A. High-value chemicals obtained from selective photo-oxidation of glucose in the presence of nanostructured titanium photocatalysts. Bioresour. Technol. 2011, 102, 11254-11257. [CrossRef] [PubMed]

25. Morishita, M.; Shiraishi, Y.; Hirai, T. Ti-containing mesoporous organosilica as a photocatalyst for selective olefin epoxidation. J. Phys. Chem. B 2006, 110, 17898-17905. [CrossRef] [PubMed]

26. Shiraishi, Y.; Morishita, M.; Hirai, T. Acetonitrile-assisted highly selective photocatalytic epoxidation of olefins on Ti-containing silica with molecular oxygen. Chem. Commun. 2005, 48, 5977-5979. [CrossRef]

27. Colmenares, J.C.; Magdziarz, A. Room temperature versatile conversion of biomass-derived compounds by means of supported $\mathrm{TiO}_{2}$ photocatalysts. J. Mol. Catal. A Chem. 2013, 366, 156-162. [CrossRef]

28. Sankararaman, S.; Yoon, K.B.; Yabe, T.; Kochi, J.K. Control of back electron transfer from charge-transfer ion pairs by zeolite supercages. J. Am. Chem. Soc. 1991, 113, 1419-1421. [CrossRef]

29. Da Vià, L.; Recchi, C.; Gonzalez-Yanez, E.O.; Davies, T.E.; Lopez-Sanchez, J.A. Visible light selective photocatalytic conversion of glucose by $\mathrm{TiO}_{2}$. Appl. Catal. B Environ. 2017, 202, 281-288. [CrossRef]

30. Nosaka, Y.; Nosaka, A.Y. Generation and detection of reactive oxygen species in photocatalysis. Chem. Rev. 2017, 117, 11302-11336. [CrossRef]

31. Shannon, R.D. Revised effective ionic radii and systematic studies of interatomic distances in halides and chalcogenides. Acta Crystallogr. Sect. A 1976, 32, 751-767. [CrossRef]

32. Andriamiadamanana, C.; Laberty-Robert, C.; Sougrati, M.T.; Casale, S.; Davoisne, C.; Patra, S.; Sauvage, F. Room-temperature synthesis of iron-doped anatase $\mathrm{TiO}_{2}$ for lithium-ion batteries and photocatalysis. Inorg. Chem. 2014, 53, 10129-10139. [CrossRef]

33. Colmenares, J.C.; Magdziarz, A.; Chernyayeva, O.; Lisovytskiy, D.; Kurzydłowski, K.; Grzonka, J. Sonication-Assisted Low-Temperature Routes for the Synthesis of Supported $\mathrm{Fe}-\mathrm{TiO}_{2}$ Econanomaterials: Partial Photooxidation of Glucose and Phenol Aqueous Degradation. ChemCatChem 2013, 5, 2270-2277. [CrossRef]

34. Colmenares, J.C.; Magdziarz, A.; Kurzydlowski, K.; Grzonka, J.; Chernyayeva, O.; Lisovytskiy, D. Low-temperature ultrasound-promoted synthesis of $\mathrm{Cr}-\mathrm{TiO}_{2}$-supported photocatalysts for valorization of glucose and phenol degradation from liquid phase. Appl. Catal. B Environ. 2013, 134-135, 136-144. [CrossRef]

35. Bellardita, M.; García-López, E.I.; Marci, G.; Megna, B.; Pomilla, F.R.; Palmisano, L. Photocatalytic conversion of glucose in aqueous suspensions of heteropolyacid- $\mathrm{TiO}_{2}$ composites. RSC Adv. 2015, 5, 59037-59047. [CrossRef]

36. Da Vià, L.; Recchi, C.; Davies, T.E.; Greeves, N.; Lopez-Sanchez, J.A. Visible-Light-Controlled Oxidation of Glucose using Titania-Supported Silver Photocatalysts. ChemCatChem 2016, 8, 3475-3483. [CrossRef] [PubMed]

37. Díez, I.; Ras, R.H. Fluorescent silver nanoclusters. Nanoscale 2011, 3, 1963-1970. [CrossRef] [PubMed]

38. Zheng, J.; Nicovich, P.R.; Dickson, R.M. Highly fluorescent noble-metal quantum dots. Annu. Rev. Phys. Chem. 2007, 58, 409-431. [CrossRef] [PubMed]

39. Aikens, C.M.; Li, S.; Schatz, G.C. From discrete electronic states to plasmons: TDDFT optical absorption properties of $\operatorname{Ag} \mathrm{n}(\mathrm{n}=10,20,35,56,84,120)$ tetrahedral clusters. J. Phys. Chem. C 2008, 112, 11272-11279. [CrossRef]

40. Chong, R.; Li, J.; Ma, Y.; Zhang, B.; Han, H.; Li, C. Selective conversion of aqueous glucose to value-added sugar aldose on $\mathrm{TiO}_{2}$-based photocatalysts. J. Catal. 2014, 314, 101-108. [CrossRef] 
41. Stapley, J.A.; BeMiller, J.N. The Ruff degradation: A review of previously proposed mechanisms with evidence that the reaction proceeds by a Hofer-Moest-type reaction. Carbohydr. Res. 2007, 342, 407-418. [CrossRef]

42. Zhou, B.; Song, J.; Zhang, Z.; Jiang, Z.; Zhang, P.; Han, B. Highly selective photocatalytic oxidation of biomass-derived chemicals to carboxyl compounds over $\mathrm{Au} / \mathrm{TiO}_{2}$. Green Chem. 2017, 19, 1075-1081. [CrossRef]

43. Omri, M.; Sauvage, F.; Busby, Y.; Becuwe, M.; Pourceau, G.; Wadouachi, A. Gold catalysis and photoactivation: A fast and selective procedure for the oxidation of free sugars. ACS Catal. 2018, 8, 1635-1639. [CrossRef]

44. Castillo, N.C.; Ding, L.; Heel, A.; Graule, T.; Pulgarin, C. On the photocatalytic degradation of phenol and dichloroacetate by $\mathrm{BiVO}_{4}$ : The need of a sacrificial electron acceptor. J. Photochem. Photobiol. A Chem. 2010, 216, 221-227. [CrossRef]

45. Wang, L.; Zhang, Z.; Zhang, L.; Xue, S.; Doherty, W.O.; O'Hara, I.M.; Ke, X. Sustainable conversion of cellulosic biomass to chemicals under visible-light irradiation. RSC Adv. 2015, 5, 85242-85247. [CrossRef]

46. Jin, B.; Yao, G.; Wang, X.; Ding, K.; Jin, F. Photocatalytic oxidation of glucose into formate on nano $\mathrm{TiO}_{2}$ catalyst. ACS Sustain. Chem. Eng. 2017, 5, 6377-6381. [CrossRef]

47. Epane, G.; Laguerre, J.C.; Wadouachi, A.; Marek, D. Microwave-assisted conversion of D-glucose into lactic acid under solvent-free conditions. Green Chem. 2010, 12, 502-506. [CrossRef]

48. Vamathevan, V.; Amal, R.; Beydoun, D.; Low, G.; McEvoy, S. Photocatalytic oxidation of organics in water using pure and silver-modified titanium dioxide particles. J. Photochem. Photobiol. A Chem. 2002, 148, $233-245$. [CrossRef]

49. Vamathevan, V.; Amal, R.; Beydoun, D.; Low, G.; McEvoy, S. Silver metallisation of titania particles: Effects on photoactivity for the oxidation of organics. Chem. Eng. J. 2004, 98, 127-139. [CrossRef]

50. Tran, H.; Chiang, K.; Scott, J.; Amal, R. Understanding selective enhancement by silver during photocatalytic oxidation. Photochem. Photobiol. Sci. 2005, 4, 565-567. [CrossRef]

51. Teoh, W.Y.; Denny, F.; Amal, R.; Friedmann, D.; Mädler, L.; Pratsinis, S.E. Photocatalytic mineralisation of organic compounds: A comparison of flame-made $\mathrm{TiO}_{2}$ catalysts. Top. Catal. 2007, 44, 489-497. [CrossRef]

52. Teoh, W.Y.; Mädler, L.; Beydoun, D.; Pratsinis, S.E.; Amal, R. Direct (one-step) synthesis of $\mathrm{TiO}_{2}$ and $\mathrm{Pt} / \mathrm{TiO}$ nanoparticles for photocatalytic mineralisation of sucrose. Chem. Eng. Sci. 2005, 60, 5852-5861. [CrossRef]

53. Fujishima, A.; Honda, K. Electrochemical Photolysis of Water at a Semiconductor Electrode. Nature 1972, 238, 37-38. [CrossRef] [PubMed]

54. Kudo, A.; Miseki, Y. Heterogeneous photocatalyst materials for water splitting. Chem. Soc. Rev. 2009, 38, 253-278. [CrossRef]

55. Kawai, T.; Sakata, T. Conversion of carbohydrate into hydrogen fuel by a photocatalytic process. Nature 1980, 286, 474-476. [CrossRef]

56. Fu, X.; Long, J.; Wang, X.; Leung, D.Y.; Ding, Z.; Wu, L.; Zhang, Z.; Li, Z.; Fu, X. Photocatalytic reforming of biomass: A systematic study of hydrogen evolution from glucose solution. Int. J. Hydrog. Energy 2008, 33, 6484-6491. [CrossRef]

57. Bellardita, M.; García-López, E.I.; Marcì, G.; Palmisano, L. Photocatalytic formation of $\mathrm{H}_{2}$ and value-added chemicals in aqueous glucose (Pt)- $\mathrm{TiO}_{2}$ suspension. Int. J. Hydrog. Energy 2016, 41, 5934-5947. [CrossRef]

58. Colmenares, J.C.; Magdziarz, A.; Aramendia, M.A.; Marinas, A.; Marinas, J.M.; Urbano, F.J.; Navio, J.A. Influence of the strong metal support interaction effect (SMSI) of $\mathrm{Pt} / \mathrm{TiO}_{2}$ and $\mathrm{Pd} / \mathrm{TiO}_{2}$ systems in the photocatalytic biohydrogen production from glucose solution. Catal. Commun. 2011, 16, 1-6. [CrossRef]

59. Zhou, M.; Li, Y.; Peng, S.; Lu, G.; Li, S. Effect of epimerization of d-glucose on photocatalytic hydrogen generation over $\mathrm{Pt} / \mathrm{TiO}_{2}$. Catal. Commun. 2012, 18, 21-25. [CrossRef]

60. Sanwald, K.E.; Berto, T.F.; Eisenreich, W.; Jentys, A.; Gutiérrez, O.Y.; Lercher, J.A. Overcoming the rate-limiting reaction during photoreforming of sugar aldoses for $\mathrm{H}_{2}$-generation. ACS Catal. 2017, 7, 3236-3244. [CrossRef]

61. Iervolino, G.; Vaiano, V.; Murcia, J.J.; Rizzo, L.; Ventre, G.; Pepe, G.; Campiglia, P.; Hidalgo, M.C.; Navío, J.A.; Sannino, D. Photocatalytic hydrogen production from degradation of glucose over fluorinated and platinized $\mathrm{TiO}_{2}$ catalysts. J. Catal. 2016, 339, 47-56. [CrossRef]

62. Bellardita, M.; El Nazer, H.A.; Loddo, V.; Parrino, F.; Venezia, A.M.; Palmisano, L. Photoactivity under visible light of metal loaded $\mathrm{TiO}_{2}$ catalysts prepared by low frequency ultrasound treatment. Catal. Today 2017, 284, 92-99. [CrossRef] 
63. Luo, N.; Jiang, Z.; Shi, H.; Cao, F.; Xiao, T.; Edwards, P.P. Photo-catalytic conversion of oxygenated hydrocarbons to hydrogen over heteroatom-doped $\mathrm{TiO}_{2}$ catalysts. Int. J. Hydrog. Energy 2009, 34, 125-129. [CrossRef]

64. Fu, X.; Wang, X.; Leung, D.Y.; Xue, W.; Ding, Z.; Huang, H.; Fu, X. Photocatalytic reforming of glucose over La doped alkali tantalate photocatalysts for $\mathrm{H}_{2}$ production. Catal. Commun. 2010, 12, 184-187. [CrossRef]

65. Zhang, L.; Shi, J.; Liu, M.; Jing, D.; Guo, L. Photocatalytic reforming of glucose under visible light over morphology controlled $\mathrm{Cu}_{2} \mathrm{O}$ : Efficient charge separation by crystal facet engineering. Chem. Commun. 2014, 50, 192-194. [CrossRef] [PubMed]

66. Li, Y.; Wang, J.; Peng, S.; Lu, G.; Li, S. Photocatalytic hydrogen generation in the presence of glucose over ZnS-coated $\mathrm{ZnIn}_{2} \mathrm{~S}_{4}$ under visible light irradiation. Int. J. Hydrog. Energy 2010, 35, 7116-7126. [CrossRef]

2018 by the authors. Licensee MDPI, Basel, Switzerland. This article is an open access article distributed under the terms and conditions of the Creative Commons Attribution (CC BY) license (http://creativecommons.org/licenses/by/4.0/). 